\title{
GEATURE ARTICLES
}

\section{中国珠宝首饰行业总览}

许春 Andrew Lucas 丘志力 李牧 于庆媛

翻译: 贾晓丹 林默青

自1978年以来, 中国经济显著增长, 巨大的商业契机吸引着世界珠宝行业的目光。继 成为珠宝首饰加工中心之后，中国的消费市场也迅速膨胀。虽然劳动力成本的提高给制 造业带来了挑战，但却带动了国内奢侈品（包括珠宝）的消费。增长潜力最大的是内地 的城市, 因为仍有大量的人口从农村迁移到这些城市。中国的消费者越来越了解珠宝首 饰的相关知识, 因此购买时也更加精明。他们对品牌和价值都有敏锐的直觉, 对当代和 西方的设计以及各种材料的态度也更加开放。同时，先进的工艺必然会提高产品质量并 且降低劳动成本, 这使中国能够满足国内甚至全球市场的需求。虽然最近的国际金融危 机影响了中国国内的消费，但中国珠宝首饰行业仍然表现出了强大的增长潜力。

中国强大的经济实力令西方世界瞩目, 同时也为 其提供了诸多发展的机遇。《纽约时报》2004年刊 登了一篇题目为“中国世纪” 的文章, 文章表达了一 种被大部分人认可的观点即本世纪初中国将会成为世 界领先的经济强国和影响力最大的国家 (Fishman, 2004）。这一趋势也同样适用于珠宝首饰行业：多年 来作为全球制造业的中心的中国现在已逐渐成为奢侈 品（例如珠宝首饰）最大的消费国。

当今, 中国消费者常被与奢侈品消费划上等号, 在珠宝首饰市场上也是如此。中国成为奢侈品消费市 场的新秀, 不同类型的珠宝首饰都能在中国市场上大 放异彩（图 1)。虽然有人预言中国在经历了三十年 爆发式的增长后会放慢增长的速度, 但是国内消费和 可自由支配收入仍然会继续增长。这些趋势加之城市 化进程的加快、中产阶级的壮大以及年轻消费者的进 一步成熟都为中国和世界珠宝首饰行业创造了机遇。

See end of article for About the Authors and Acknowledgments. Gems \& Gemology, Vol. 50, No. 1, pp. 2-29, http://dx.doi.org/10.5741/GEMS.50.1.2.

(C) 2014 Gemological Institute of America
中国因此也必须要解决一些问题, 例如要开发足够多 的宝石资源以满足进出口的需要（图2）。

\section{经济概况}

2010年，中国超过日本成为仅次于美国的世界第 二大经济体（表1）。总体来说, 过去30年中国经济

\section{表1. 2012 年国民生产总值排名前十位的国家}

\begin{tabular}{ccc}
\hline 排名 & 国名 & 万亿 \\
\hline 1 & 美国 & 15.684 \\
2 & 中国 & 8.227 \\
3 & 日本 & 5.959 \\
4 & 德国 & 3.399 \\
5 & 法国 & 2.612 \\
6 & 英国 & 2.435 \\
7 & 巴西 & 2.252 \\
8 & 俄罗斯 & 2.014 \\
9 & 意大利 & 2.013 \\
10 & 印度 & 1.841 \\
\hline
\end{tabular}

世界银行统计数据 (2013) 


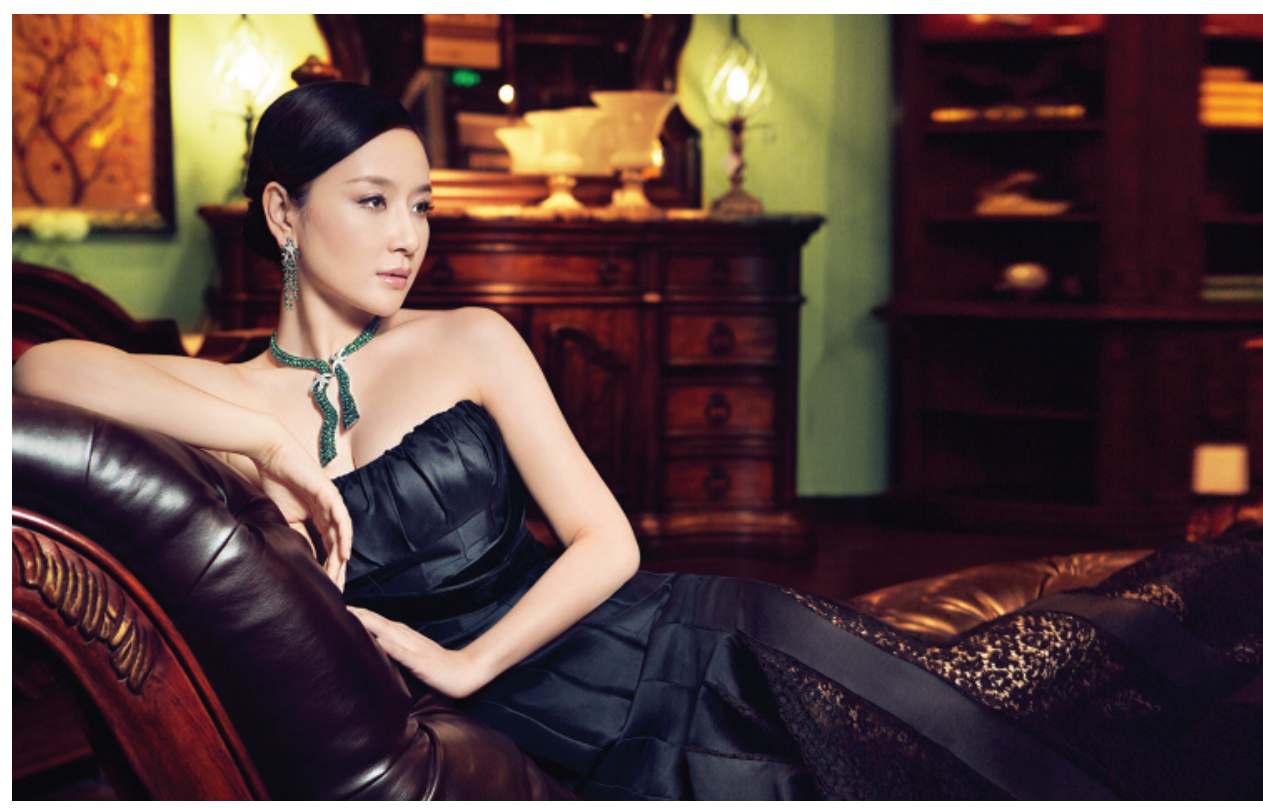

图 1. 著名影视演员孙宁诠释 品牌Enzo的高端珠宝。成立 于香港的Enzo是知名的彩色 宝石珠宝品牌。后来该公司 发展成为大陆著名的珠宝零 售品牌，其业务涉及从采 矿到零售的各个环节。图片 由富安门摄影的欧阳拍摄, 由《中国宝石》供图。品牌 珠宝由Enzo提供。

的平均年增长率为 10\%左右（Barnett，2013）。据 中国国家统计局的数据显示, 2013年上半年的国内 生产总值（GDP）是4万亿美元，与上年同期相比增 长了 7.6\%。彭博资讯高级经济师Michael McDonough 准确地预测了中国政府2013年下半年将会允许经济 增长速度的放缓, 因为政府的策略是将重点转移到更 加稳健的经济的长期增长上。

$7.6 \%$ 的预期增长率与过去三十年两位数的增长 率相比似乎低了一些，但与美国、欧洲以及日本的 增长率相比还是令人羡慕的。作为拥有全年高达 8 万

图 2. 中国近来在出口和国内市场上对宝石的大量消费引 起了宝石供应的短缺现象, 这一现象也促使世界范围内的 矿源地和市场上的竞争更加激烈。照片由Andrew Lucas 拍摄。

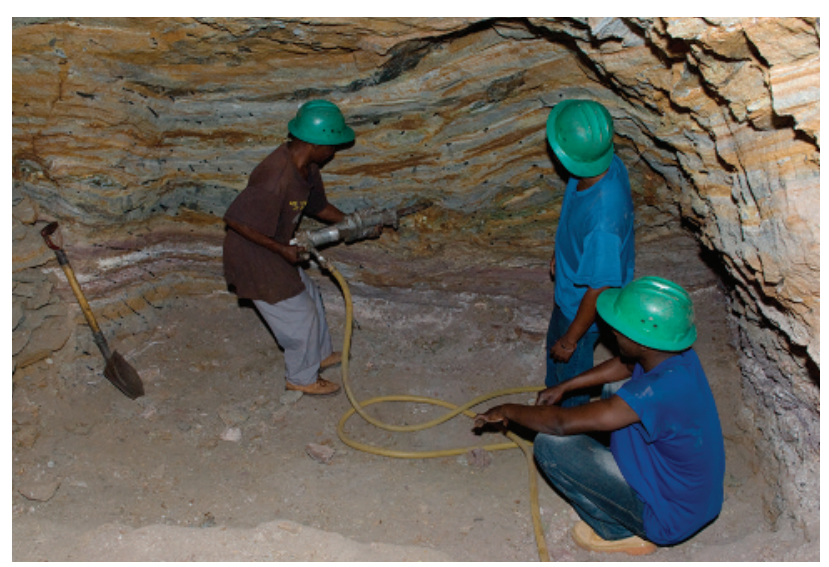

亿美元GDP的世界第二大经济体来说，这一预期还 是合理的。一些经济师同时还预测 2020年至2030 年间中国将会超越美国成为世界第一大经济体 (Shamim, 2010)。国际货币基金组织（IMF）预测 的时间为 2020年之前。当然, 这一目标实现的时间 最终还要取决于未来经济的增长率, 而增长率预计 将会放缓。

制造业。2010年中国已经成为世界最大的制 造中心（图3），2012年全年的工业生产总值扩 大到了2.9万亿美元，超过了美国的2.43万亿美元

图 3. 中国是世界上最大的加工基地, 当然也是最大的珠宝 首饰加工国。在这座位于中国广东省的现代化首饰加工厂 里, 工人们加工品种繁多的珠宝首饰。照片由Eric Welch 拍摄, 场地由周大福珠宝提供。

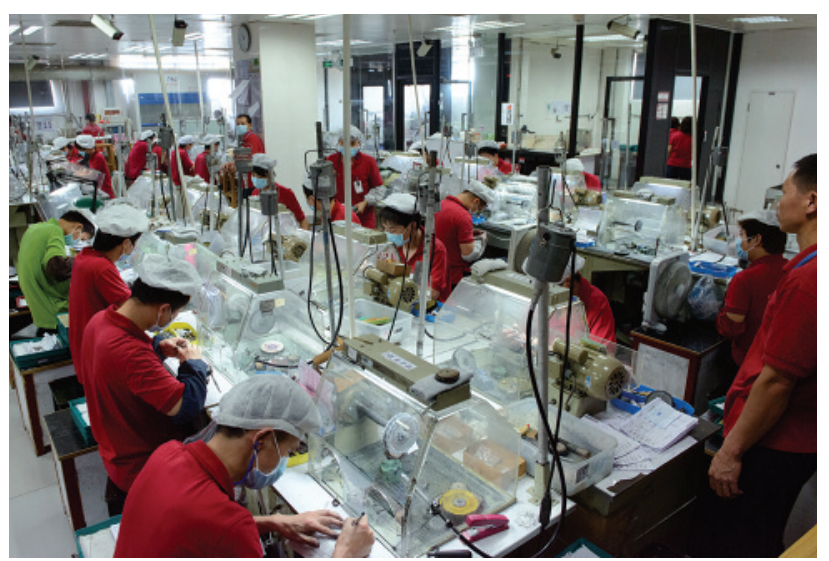


表2.中国经济从1979年到 2012 年的增长情况

\begin{tabular}{|c|c|c|c|c|}
\hline 年份 & $\begin{array}{l}\text { 国民生产总值 } \\
\text { (万亿美元) }\end{array}$ & $\begin{array}{c}\text { 国民生产总值增长率 } \\
\text { (\%) }\end{array}$ & $\begin{array}{c}\text { 人均国民生产总值 } \\
\text { (元) }\end{array}$ & $\begin{array}{c}\text { 人均可支配收入 } \\
\text { (元) }\end{array}$ \\
\hline 1979 & 0.1766 & 7.6 & 419 & 387 \\
\hline 1980 & 0.1896 & 7.8 & 463 & 477 \\
\hline 1981 & 0.1941 & 5.2 & 492 & 491 \\
\hline 1982 & 0.2032 & 9.1 & 528 & 526 \\
\hline 1983 & 0.2284 & 10.9 & 583 & 564 \\
\hline 1984 & 0.2574 & 15.2 & 695 & 651 \\
\hline 1985 & 0.3067 & 13.5 & 858 & 739 \\
\hline 1986 & 0.2978 & 8.8 & 963 & 899 \\
\hline 1987 & 0.2704 & 11.6 & 1,112 & 1,002 \\
\hline 1988 & 0.3095 & 11.3 & 1,366 & 1,181 \\
\hline 1989 & 0.344 & 4.1 & 1,519 & 1,373 \\
\hline 1990 & 0.3569 & 3.8 & 1,644 & 1,510 \\
\hline 1991 & 0.3795 & 9.2 & 1,893 & 1,700 \\
\hline 1992 & 0.4227 & 14.2 & 2,311 & 2,026 \\
\hline 1993 & 0.4405 & 14 & 2,998 & 2,577 \\
\hline 1994 & 0.5592 & 13.1 & 4,044 & 3,496 \\
\hline 1995 & 0.728 & 10.9 & 5,046 & 4,283 \\
\hline 1996 & 0.856 & 10 & 5,846 & 4,838 \\
\hline 1997 & 0.9526 & 9.3 & 6,420 & 5,160 \\
\hline 1998 & 1.0195 & 7.8 & 6,796 & 5,425 \\
\hline 1999 & 1.0833 & 7.6 & 7,159 & 5,854 \\
\hline 2000 & 1.1985 & 8.4 & 7,858 & 6,280 \\
\hline 2001 & 1.3248 & 8.3 & 8,622 & 6,860 \\
\hline 2002 & 1.4538 & 9.1 & 9,398 & 7,702 \\
\hline 2003 & 1.641 & 10 & 10,542 & 8,472 \\
\hline 2004 & 1.9316 & 10.1 & 12,336 & 9,421 \\
\hline 2005 & 2.2569 & 11.3 & 14,185 & 10,493 \\
\hline 2006 & 2.713 & 12.7 & 16,500 & 11,759 \\
\hline 2007 & 3.4941 & 14.2 & 20,169 & 13,786 \\
\hline 2008 & 4.5218 & 9.6 & 23,708 & 15,781 \\
\hline 2009 & 4.9913 & 9.2 & 25,604 & 17,175 \\
\hline 2010 & 5.9305 & 10.4 & 29,748 & 19,109 \\
\hline 2011 & 7.3219 & 9.2 & 35,083 & 21,810 \\
\hline 2012 & 8.2271 & 7.8 & 38,354 & 24,565 \\
\hline
\end{tabular}

数据来源: 2013 年世界银行统计数据及 2013 年中国珠宝年鉴 (http://finance.people.com.cn/n/2013/0904/ c1004-22803247.html）（Sims, 2013）。这其中 一个主要原因是中国国内消费的迅猛增长。

城市中心。中国的城市总体来说可划分为四级。 一线城市（图4) 是最现代化和国际化的大都市; 包 括上海、北京、深圳和广州。其他几级城市财富总量 相对较少、工资水平较低, 可自由支配收入较少, 基 础设施较不完善, 便利设施较不完备, 资源相对缺 乏。据非官方的数据显示, 中国的二线城市大约有 59 个, 三线城市 92 个, 四线城市有 105 个 (Schuster, 2012)

图 4. 广州等中国的一线城市一直以来都是经济增长的主 要驱动力。坐落于珠江边的广州电视塔象征了这座城市的 经济实力。照片由 Eric Welch 拍摄。

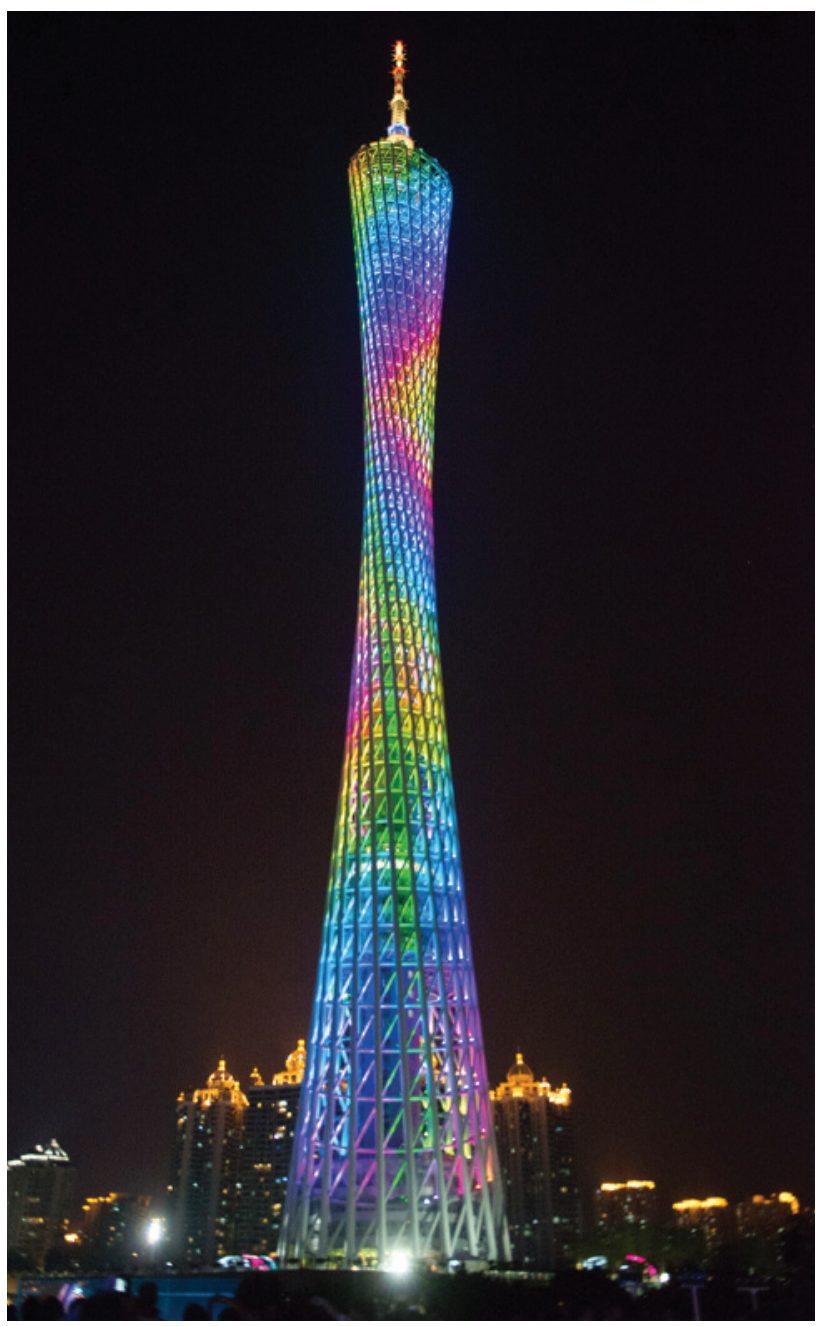


二线城市正在快速地发展成为新的商业中心, 这 也重塑了国家商业、工业和监管的格局(Schuster, 2012)。随着一线城市工人的工资水平和土地价格的 上涨, 制造业已经向非一线城市转移。政府的改革措 施也鼓励企业向这一方向发展。因为这样可以为新兴 的城市创造更多的就业机会及提供更多的资源, 消费 者的工资高了, 可自由支配的收入也会随之提高, 相 应的可自由支配的开支也就会更多。可自由支配的开 支中有相当大的一部分会被用于购买首饰。中国主要 的珠宝零售企业如周大福、周大生很多年前就已经意 识到这些非一线城市的消费潜力并已积极地将工厂向 这些城市集中。

特别行政区。香港和澳门是中国仅有的两个特别 行政区（SARs）。香港曾经是英国的殖民地，而澳门 曾经是葡萄牙的殖民地。它们先后于 1997 年和 1999 年回归中国并实行“一国两制”的政策。因为他们特

\section{提要}

- 中国不仅是全球最大的加工中心，其消费 市场也以惊人的速度膨胀。

- 随着城市化进程的加快、中产阶级的壮大 以及年轻的奢侈品消费者的进一步成熟, 中国可能很快就会成为世界最大的珠宝首 饰消费市场。

- 利于行业发展的税收改革, 钻石交易所的 成立, 以及专业人才的培养和实验室标准 的建立, 令中国珠宝首饰行业的国际竞争 力越来越强。

殊的地位，香港和澳门享有高度的自治权。虽然经济 学上通常将中国内地和香港分开进行研究, 但是他们 作为一个国家的整体性不容忽视。两者的商业往来早 在1997年主权交接之前就已经建立了, 尤其是在20 世纪70年代中国开展了一系列重大的经济改革之后。 很多香港本土的企业纷纷在中国大陆开办工厂, 有 一些工厂就在紧邻的深圳, 因为这里有相对廉价的劳 动力（图5）。

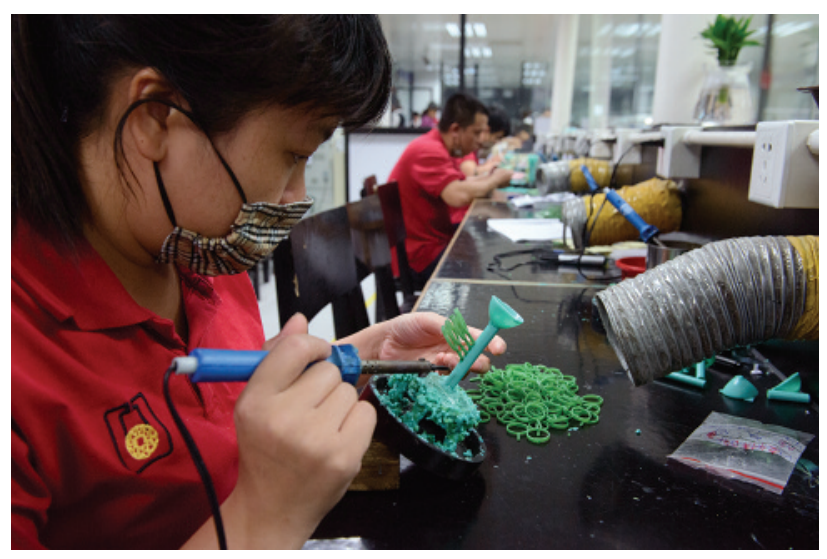

图 5.广东由于吸引了大批香港公司的进驻而成为世界重 要的首饰加工中心。在这家现代的首饰加工厂里, 工人能 够熟练运用雕蜡和失蜡浇注等现代首饰加工技术。照片由 Eric Welch拍摄。场地由周大福珠宝提供。

中国内地在1978年改革开放后不久建立了经济 特区（SEZs），其优点是将廉价劳动力和自由贸易联 系起来。改革还促进了自由市场经济的发展并建立了 灵活的经济政策，尤其对制造业和出口行业的影响更 为明显。深圳和广东的番禺都设有面向钻石、宝石和 首饰行业的重要经济特区。这些地方生产的产品很多 都会通过香港销往世界各地。另一个重要的经济转折 点是2001年, 这一年中国加入了世界贸易组织, 这 不仅移除了贸易堡垒还为中国的商品提供了更广阔的 市场。

五年计划。从1953年起, 中国政府已经编制了 一系列针对经济和社会发展的五年计划纲要。“十二 五”规划正在实施，时间从2011年到2015年。“十 二五” 规划将减少对出口的依赖, 通过扩大国内消费 来保持经济的增长速率。这份最近的经济计划强调可 持续的低增长, 同时更多的依赖于国内市场。现行的 五年计划（KPMG China，2011）列举了影响中国经 济的几项主要的战略举措，其中包括：

- 高质量的增长: GDP增长率的目标已经降低 到 $7 \%$ 左右, 并重点解决之前快速增长所带来的一些问 题, 例如环境问题、资源枯竭和能源过渡开发问题。

- 共享式的增长：为了缩小个人和地域之间的 经济差距, 在经济增长的同时要创造更加平等的发展 机遇。 
- 非一线城市和西部地区的发展: 注意力从一 线城市（主要是沿海城市）转移到其他非一线城市以 及西部欠发达地区，这一举措已经卓有成效。

- 从出口导向型经济转变成消费驱动型经济: 现在的计划强调, 国家要从依赖出口的经济增长模式 转变成扩大国内消费市场的经济增长模式。

- 城市化率从 $47.6 \%$ 增长到 $61.6 \%$ ：主要是农村 人口向非一线城市迁移。

可自由支配收入。从2000年到2011年间，中国约 有 2.3 亿人口迁移到了城市, 这被认为是历史上最大 规模的城市化人口迁移（Rare Investment, 2013）。 预计从2012年到2047年，城市居民可支配收入平均 每年将增长13\%。根据中国国家统计局的资料，在 2010年到2020年间, 非生活必需品的消费量也会相 应的以每年13\%的速度增长（Barton et al, 2013）。中 国的可自由支配收入的增长率一直都低于GDP的增长 率（图6）。

图 6.中国的人均可支配收入的增长一直滞后于人均国民 生产总值的增长。数据来源于世界银行及中国珠宝年鉴。

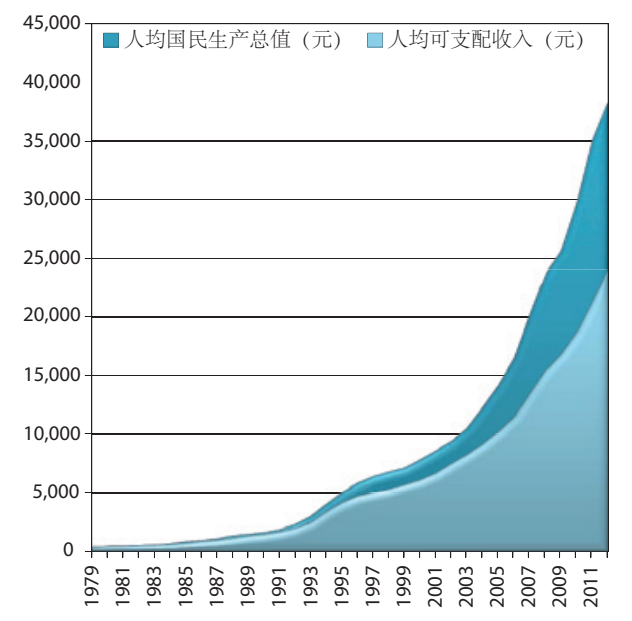

根据中国国家统计局的资料，居民可支配收入的 增长一直以来主要都是由最高收入的人群贡献的, 高 收入人群和上层中产阶级紧随其后, 比例分别为 $14.5 \% 、 12.8 \%$ 和 $12.1 \%$ 。这些人也是奢侈品最主要 的消费群体，并且对优质的商品有强烈的需求（Fung Business Intelligence Center, 2013）。高收入人群 可自由支配收入的增长率也更快。

人口分布。中国今后的经济增长主要依靠国内消 费。中产阶级的崛起推动了商品和服务性消费的快速 增长。2012年中国的中产阶级大约有2.25亿, 到 2025年，预计会增加到3.3亿（Schuster, 2012）。 按百分比来看, 中产阶级数量增长最快的将会是内地 的二线和三线城市（Barton et al., 2013）。

中国新兴的中产阶级也可以划分为几个年龄段。 净资产超过 1000 万元的个人的平均年龄为 39 岁。净 资产超过 1 亿的个人的平均年龄为 41 岁 (Fung Business Intelligence Centre, 2013）。中国的第二代（ G2）由十多岁的青少年和二十出头（19世纪80年代 中出生) 的年轻人组成, 人数有 2 亿左右。这些人代 表了大约15\%的城市消费者(Barton et al., 2013)。到 2022年，二代的人数预计会达到美国婴儿潮时期的 人口数量的三倍以上，并且占到国内消费市场的 35\%(Barton et al.,2013)。这些年轻人的消费观念更加 西化。他们对自己的收入前景很乐观, 热衰于品牌消 费, 乐于尝试新鲜的事物, 并且习惯网购（图7）。

中产阶级人口数量的增加势必会刺激国内消费。 2002年, 当时中国的中产阶级人数相对较少, 而其 中的 $40 \%$ 集中在以下四个城市：北京、上海、广州和 深圳。由于北部和西部地区, 尤其是三线城市中产阶 级数量的迅速壮大, 预计到2022年, 这一比例会降 到 16\%（Barton et al., 2013）。通过对比上层中产 阶级的增长与个人消费的预计增长, 中产阶级购买力 的重要性是显而易见的（图8）。

根据全球管理咨询公司麦肯锡的报告, 如图9所 示, 国内消费组成中最重要的人群就是上层中产阶级 


\section{中国城市年轻消费者的西化消费观念}

答卷人百分比城市中等及富有阶级, 口城市中产阶级 ${ }^{2}$ “城市总体情况
第二代” ${ }^{1}$
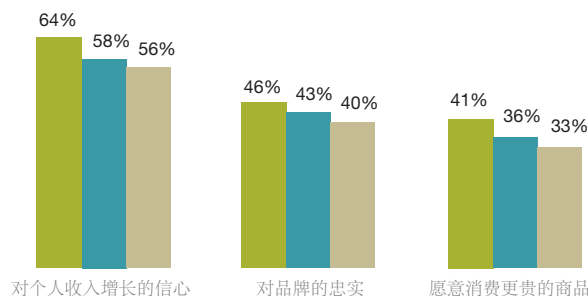

原意消费更贵的商品

对品牌的忠实

愿意

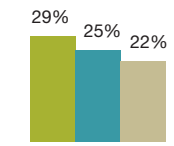

对新兴产品和服务接受很快

${ }^{1}$ 在1 985 年以后出生的人, 其生活环增相对富足。

2年收入在1 0600 到 229000 元之间 (大踭等于 2010 年的1 6000 到 34000 美元)

${ }^{3}$ 以个人日用品的消费为例

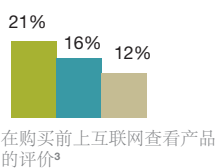

图 7.被称为“第二代”的年 龄在十几到二十几岁的消费者 是中国消费市场新生的重要 消费群体。针对 10000 名年轻消费者的这项调查结 果表明这些消费者的消费观 念可能在未来会改变商家对 产品的宣传策略和销售方 式。图表改编自Barton et al., 2013,来源于McKinsey \& Company的调研报告。
（Barton, 2013）。报告中定义的上层中产阶级是 年收入在 60,000到 106,000元之间的中国公民。同 样的一份报告指出，到2022年，上层中产阶级的消 费将会占到城市家庭消费的 $56 \%$ 。正如富人阶层和 巨富阶层一样，上层中产阶级的消费者将会对奢侈 品市场的增长做出贡献。奢侈品市场在过去的几年 里已经以每年16-20\%的速度增长了（Barton et al., 2013）。到2015年, 中国奢侈品消费（包括国内 和国外）将会占全球首饰和其他奢侈品消费市场份
额的三分之一。

上层中产阶级是中国消费者中最西方化的。他们 乐于尝试新鲜的事物, 并且认为昂贵的商品本身更有 优势。中国正在壮大的中产阶级也认为, 将可自由支 配的收入用在购买奢侈品上是体现社会地位的一个必 不可少的元素。

中国的消费市场在人口统计学上的另外一个特点

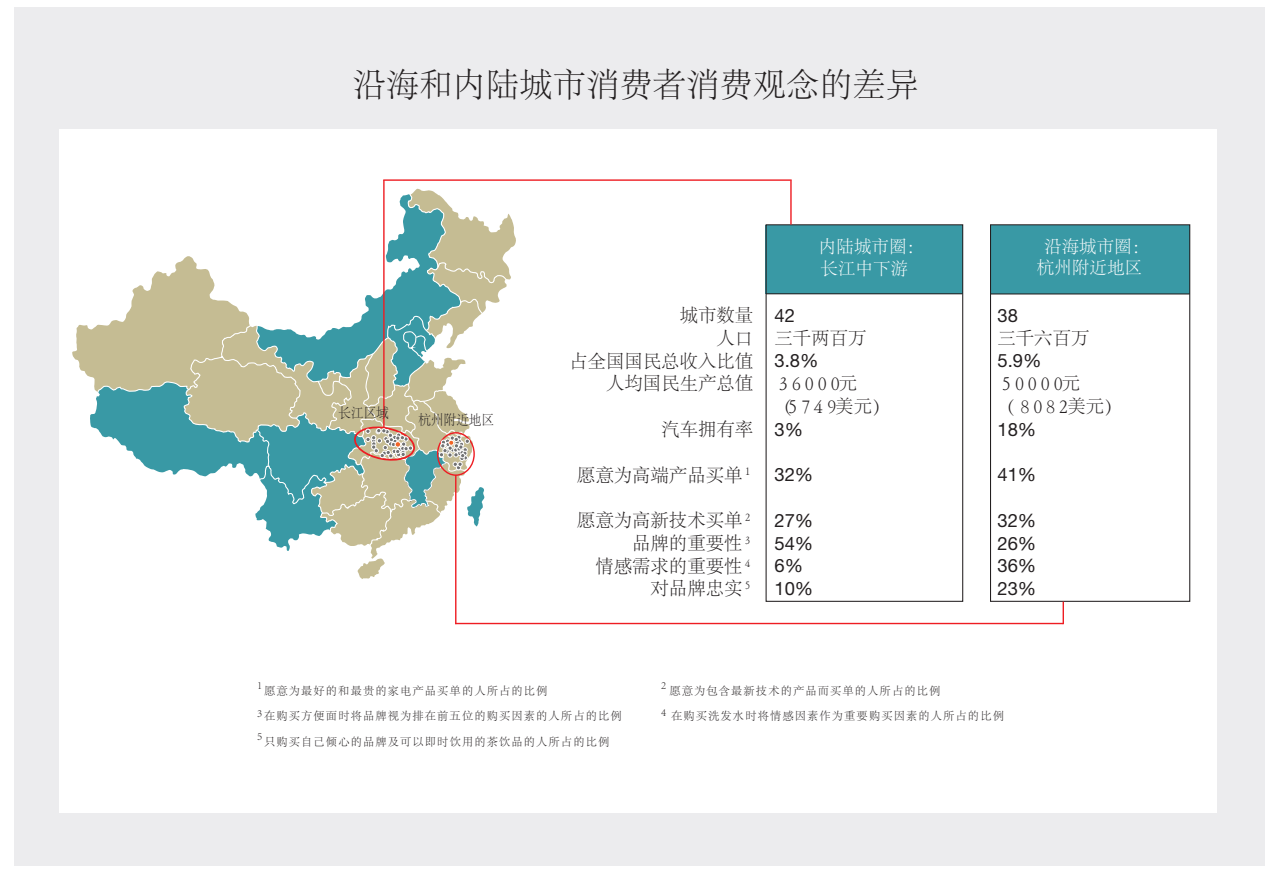

图 8. 通过对比长江中下游的 内陆城市和沿海城市, 消费 者消费态度的差别还是很明 显的。图表改编自Atsmon et al., 2012, 来源于McKinsey\&Company的调研报告。 


\section{中国各个收入阶层的变化}

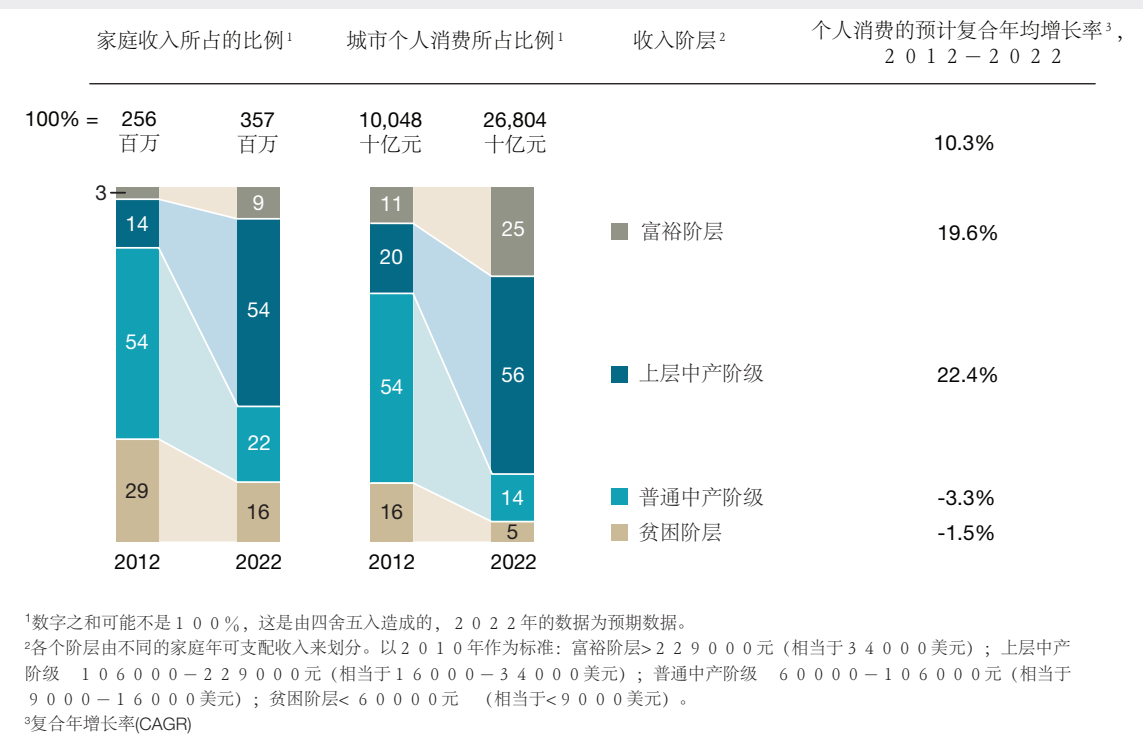

图 9. 中产阶级的不断壮大 正在通过对国内消费的带动 而改变着这个国家。改编自 Barton et al., 2013; 来源于 McKinsey \& Company。
是女性为家庭收入所做的贡献正在增加。到2009年, 女性对家庭收入的贡献已经达到了 50\%（Shaun Rein, pers. comm., 2013）, 同时四分之三的中国女性称她 们控制着家庭的财务 (Georgette Tan, pers. comm., 2013）。

国内消费。据中国市场分析师预测，居民用于投 资和消费的收入比例将会有所转变（图 10）。2000 年到 2010 年间，投资占GDP增长的 $53 \%$ ，而个人 消费的比例仅占 $27 \%$ 。这一比例预计将会在 2020 到2030年间有很大的转变, $34 \%$ 的资金会用于投 资，而51\%的资金将用于个人消费（Woetzel et al., 2012）。

政府希望人民的工资即使不能超过GDP的增长速 度, 也至少要与之持平。2012年上半年, 中国约有 五分之四的省份将最低工资提高了 19.7\%（Woetzel et al.,2012）。虽然人工成本的提高也为政府在制造 业的全球竞争力造成了挑战, 但是改革的方向也十分 明确, 因为中国国内的购买力和消费的增长几乎是册 庸置疑的。

麦肯锡2011年的调查（Atsmon et al., 2011）揭 示了几个具有启发性的事实:

- 中国的消费者常常能够很快适应新的或之前 不太熟悉的商品。
- 中国消费者对品牌的认知度不断上升, 但对 品牌的忠诚度并没有提高。在中国, 品牌必须赢得信 任。研究显示中国的消费者并不是盲目地对品牌忠诚, 如果其他品牌能够赢得他们的信任, 他们愿意更换品 牌一一这一点对比西方人来说更加明显。很多中国的 消费者会从几个喜爱的品牌中挑选合适的商品。

图 10. 作为中国经济增长的重要贡献的个人消费被预计将 取代投资成为国民生产总值中所占比例最大的部分。改编 自Woetzel et al., 2012, 来源于McKinsey \& Company。

\section{消费与投资在国民生产总值中所占的比例}

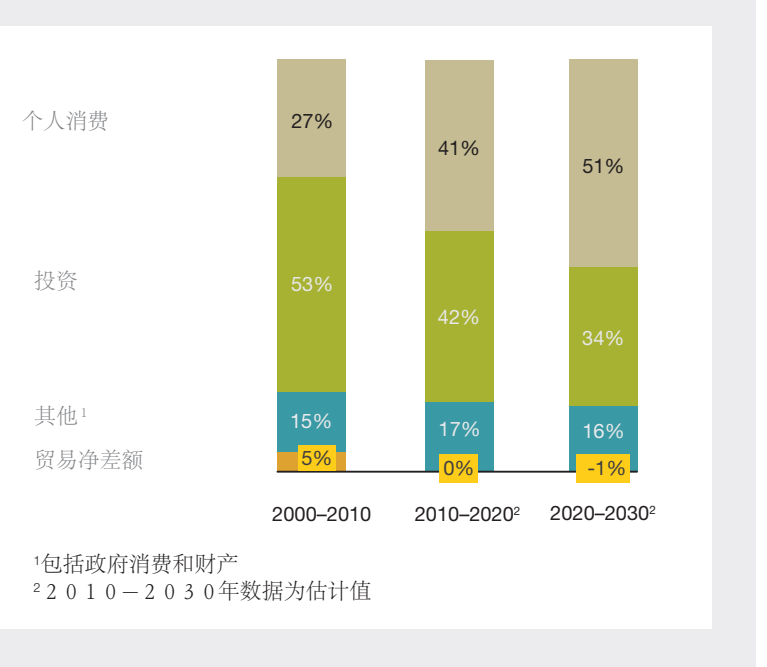




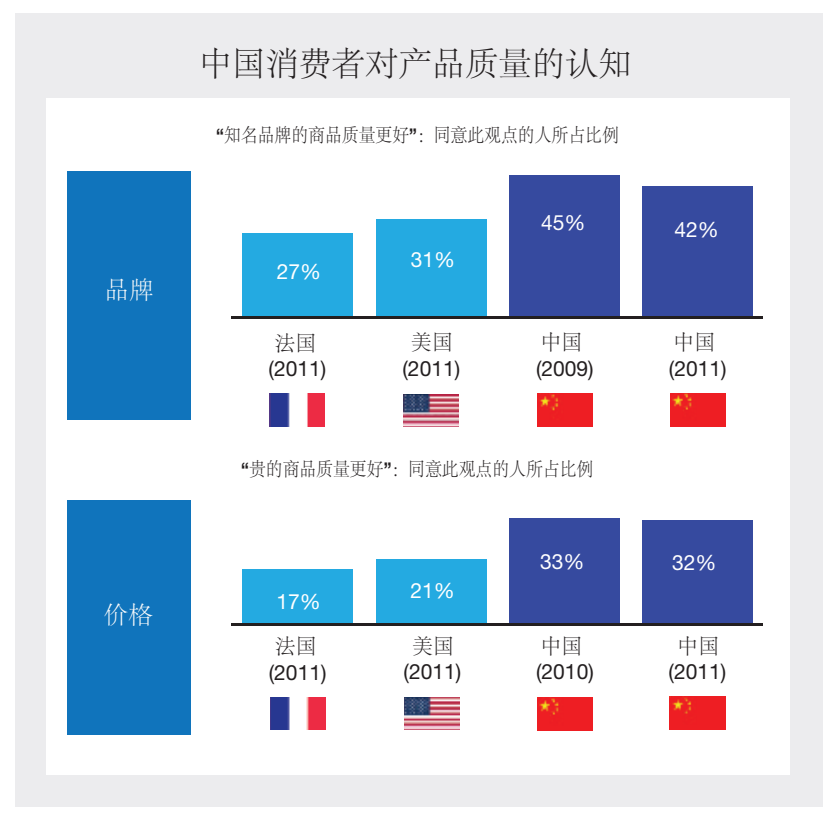

图11. 很多中国消费者信赖知名, 高价品牌商品的品质。改 编自Atsmon et al., 2011; 来源于McKinsey \& Company。

・ 价格同样也发挥了很重要的作用（图 11）。 中国的消费者不追求价格低廉的商品, 但并不表示他 们不会考虑性价比。

- 社交媒体的普及程度以惊人的速度逐年增 长。到2011年中, 新浪微博（相当于Twitter）已经 拥有 1.95 亿中国用户。这一数字是六个月前的三倍。 即时通讯工具WeChat（中文也叫做微信）于2010年 初正式推出, 用户的增长速度甚至超过微博。据CNN 报道, WeChat推出后 15 个月内注册用户已经高达 1 亿, 到 2013 年九月每天的活跃用户人数已达 2.719 亿 （Skuse, 2014）。现在人们甚至可以通过微信进行 买卖, 模式与易趣 (eBay) 相似。

- 2011年, 对于高收入的消费者（仍然低于美 国高收入人群的收入) 而言, 在品牌选择和购买行为 中情感因素起着很重要的作用, 预计这一趋势还会继 续。

- 虽然2011年面临了经济挑战, 但中国消费者 对他们的经济前景越来越有信心。

麦肯锡公司的此份调查还为那些未来希望在中国的
经济增长中谋取自身发展的公司提供了有用的建议。

- 优先的增长机遇。虽然很多公司的的注意力 都集中在一线城市，但是约60\%的日用消费品都是在 非一线城市出售的。

- 紧抓机遇制定有针对性的营销方案。区域性 偏好和可支配收入的差异表明在中国利用统一的策略 是行不通的, 需要根据不同的区域制定不同的优化方 案。

- 关注认知价值, 而非价格。中国的消费者似 乎对价格尤其敏感。低价格往往意味着低品质。中国 消费者认为物有所值才是最重要的。

- 吸引大众的目光和满足特殊消费群体。随着 中国消费者的辩识能力越来越强, 产品必须有针对 性。企业如果能够针对不同的消费群体推出不同的产 品, 就为今后的发展打下了很好的基础。

- 有时代感的营销手段。尽管电视广告等传统 广告媒体比较昂贵, 但在中国非常有效。过去, 与西 方国家相比, 电子商务和社交媒体在中国受认可的速 度比较缓慢, 但是近几年网络零售业和社交媒体中的 零售业已经实现了飞速增长。因此, 对网络营销投入 更多的精力很可能会实现更快的增长。

进口和出口。在对189个国家经商便利度进行的 排名中, 中国排在第96位（World Bank, 2013）; 美国排在第4位，而印度排在第134位。其实中国的 排名并不能说明所有的问题。因为中国有巨大的增长 潜力, 很多外国公司都在中国开展业务。此外, 香港 作为特别行政区拥有自己的交易规则, 它在这项报告 中排名第二, 而中国的很多贸易往来都是通过这一自 由贸易区来完成的。正如前面提到的, 很多香港的公 司迁到了中国内地, 部分原因是制造和出口费用低, 同时更靠近国内的消费市场。

中国是仅次于欧盟的世界第二大出口国 (Central Intelligence Agency, 2013）。此外, 中国也是仅次 于欧盟和美国的世界第三大进口国。这些数据证明了 
中国在世界贸易中的重要地位。

奢侈品。大中华区, 包括香港和澳门, 是世界第 二大奢侈品消费区。中国消费者购买的奢侈品占亚洲 奢侈品消费总量的一半，是欧洲奢侈品消费总量的三 分之一（Bain \& Company,2012）。美国奢侈品消费 量的增长一部分也是被中国游客带动的。据预测中国 的奢侈品消费市场将会日趋成熟, 但无论是在国内还 是全球市场中还会保持增长, 因为中国游客会去国外 例如巴黎、纽约和夏威夷旅行和购物。

2012年中国奢侈品消费增长放缓，部分原因是 随着经济的复苏, 中国游客在境外购买的奢侈品数量 增多。我们在本次调研中还了解到一些政府出台的新 规定, 即不许政府官员浪费和炫富, 这些规定也对奢 侈品消费带来了一些负面的影响。

同时，中国的消费者在消费习惯上也变得更加精 明, 从以前只购买那些有名的大品牌到追求奢侈品 的品质和价值（Bain \& Company, 2012）。尽管中 国奢侈品市场仍十分看重品牌的象征意义, 但品牌 想要取得长足发展还需展现其自身价值。一线和二 线城市的消费者不仅会考虑品牌的知名度, 还会追 求品质、价值、个性和低调。三线和四线城市的消 费者可能缺少经验, 仍然会追求有明显标识的知名 品牌。但长远来看品牌的文化内涵而非商标才是消 费者越来越重视的方面（Fung Business Intelligence Centre, 2013)。

奢侈品品牌的消费主力军从年龄稍长的商务男 $士$, 转变为年轻购买者和女性 (Bain \& Company, 2012）。60\%的奢侈品消费者年龄在20到39岁之 间，而欧洲这一年龄段的比例为38\%（Fung Business Intelligence Centre, 2013）。只有7\%的中国奢侈品 消费者的年龄超过60岁，相反在西欧这一比例为 $21 \%$ (Hurun, 2013).) 。值得注意的是, 在中国个人收 入超过 1000 万的人群中女性的比例为 40\%。这些富 裕的中国女性在奢侈品上的开销从2010年的25\%增 长到2012年的46\%（Lui et al., 2012）。
中国消费者对奢侈品牌的态度

您有计划购买奢侈品牌的商品吗?

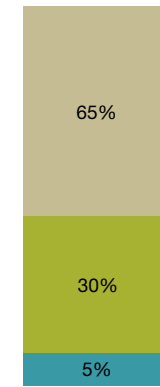

北京和上海的消费者

口有没有决定

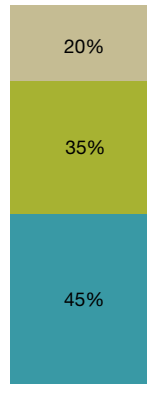

其他城市的消费者

口没有
图12. 中国三、四线城市的消费者比一、二线城市的更愿意 购买奢侈品牌的产品。改编自Bain \& Company(2012)。

互联网零售。在过去几年里电商在中国发展迅 猛, 销售的产品中就包括服装、电子商品和珠宝首饰 等。三线和四线城市的居民比一、二线城市居民网购 方面的花费占可支配收入的比例更高（Dobbs et al., 2013）。中国在线钻石销售的先行者钻石小鸟用多 年时间树立起消费者对在线购买的信心。西方很多奢 侈品珠宝零售企业, 包括卡地亚、宝格丽和蒂凡尼, 它们的粉丝数量在社交媒体的奢侈品品牌中都名列前 茅（图 13）。

中国电商在2013年末有一次显著的增长, 年末 有一个非官方的节日被称作“光棍节”。11月11日 代表单身人士。多年来, 这一天都是中国大批单身人 士进行庆祝的日子。2008年, 中国的电商巨头阿里 巴巴开始在光棍节开展推广活动。（阿里巴巴旗下的 两个网站, 淘宝和天猫的交易量比亚马逊和易趣加起 来还要多。）很快, 中国很多其他的电商网站纷纷效 仿，为消费者提供各种类型的商品。据统计，2013 年光棍节当天的成交额超过了 57.5 亿元, 成为电子商 务史上成交量最大的一天，远远超过美国2012年的 网购星期一(感恩节假期之后的第一个上班日的网购 促销活动)（Wang and Pfanner, 2013）。 


\section{新浪微博上一些奢侈品牌的关注度排名（数据统计截止到 2013 年 3 月 18 日)}

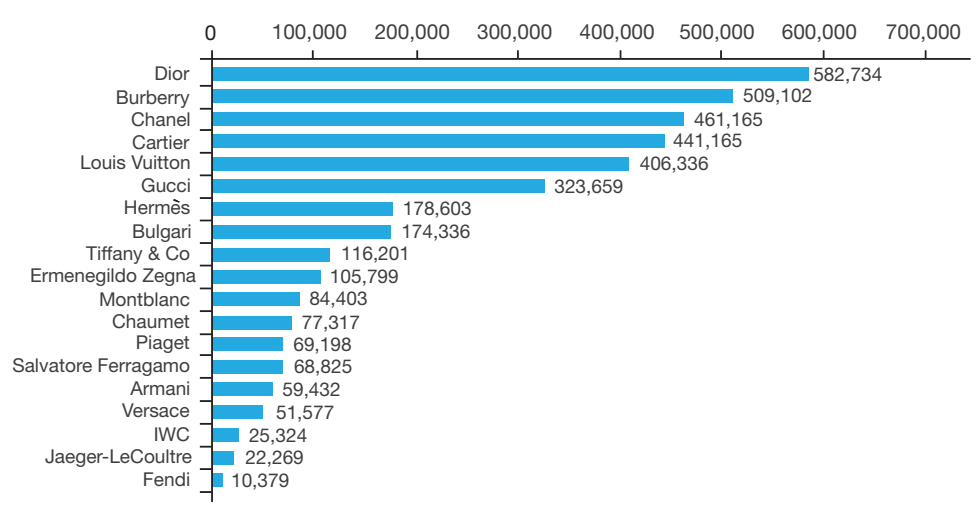

图13. 几个西方知名珠宝品 牌在新浪微博上都排在最受 关注的品牌之列。改编自 Fung Business Intelligence Center (2013)。

注：这里只包括在新浪微博有注册账号的奢侈品牌

2013年光棍节仅阿里巴巴一家就有4.02亿的访问 量, 邮寄了 1.52 亿件包裹。其中珠宝和首饰也扮演了很 重要的角色。举例来说, 浙江省的一位女士花了 337 万元购买了 13.33克拉的钻石 (Wang and Pfanner, 2013）。

\section{中国的珠宝首饰行业}

历史回顾。中国的珠宝和首饰有完整的发展史, 金和银作装饰品已经至少有3000年的历史了。根据 考古学的证据, 中国使用玉的历史更加久远, 从新石 器时代就开始了（Zhang, 2006）。

随着制造业技术的发展，从最早商代（约 $1700-1100 \mathrm{BC}$ ）墓穴中发现的简单的金片和金叶到 汉代和唐代（265-907）用东方和西方元素来进行装 饰的精巧的首饰。早期的金属工艺在明代和清代到达 了顶峰（1368-1912），当时为皇亲国戚制作奢华的 金银器和首饰的工艺也继承到了现代。

清代早期翡翠从缅甸传入中国, 在这之前史书中 记载的 “玉”指的是软玉。因为软玉特殊的颜色、光 泽和结构, 人们认为它代表了中国文化和中国人所崇 尚的品质。玉最先被用作工具和礼器, 之后逐渐用于 实用性的器具、首饰和雕刻品。
清代皇帝对翡翠的钟爱对后世影响深远。历史 上, 翡翠从缅甸进口到中国有两条途径: 一条是通过 中国西南的两国边境, 另一条是通过广州口岸, 广州 因此也成为了翡翠交易之都。从1873年到1878年, 每年约有200吨的翡翠通过广州进口到中国（Li， 2013）。现在，广州是著名的翡翠加工和交易中 心，揭阳、四会和平洲是最活跃的几个地区。

图 14. 这对 $24 \mathrm{~K}$ 金的护甲是清朝时期皇家作品的复制品。照 片由Eric Welch拍摄；护甲由昭仪翠屋提供。

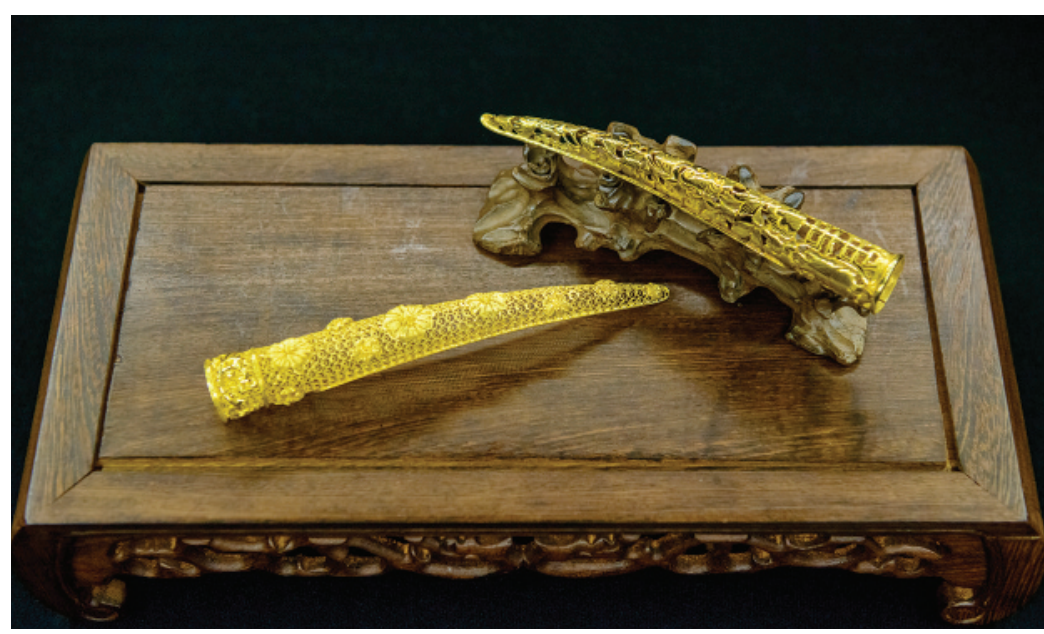


现代珠宝首饰行业。纵观中国的历史, 小型作坊、 以及皇家的制作和加工工厂占据了主导地位。一旦皇 帝委任工厂制作一件物品, 该物品就会被打上标记, 不能私下买卖。这种强制性的规定阻碍了中国珠宝首 饰行业的发展。

现代中国珠宝首饰行业的开端以“银楼”的出现 为标志, 从清代末期开始直到1949年中华人民共和 国成立，贵金属的制造商和商人在此进行私人买卖。 大多数银楼同时也是当铺。第一次鸦片战争（18401842）英国成功地打开了中国市场和社会的大门, 同时也拉开了中国现代工业的序幕。因为接触到了西 方工业革命一系列突破性的成果（约1760-1840）, 中国也开始建立现代化的工厂和商业。

在鸦片战争之前, 御用的加工厂受皇家管辖, 而 银楼是由私人投资开办的, 没有数量和规模的限制。 甚至有一个专业的行业协会指导商人如何与其他行业 或政府打交道。

20世纪初清代晚期，很多商人已经建立起自己的 商业声誉并且成为行业内的翘楚。在上海, 9 个具有 代表性的银楼于1896年成立了一个珠宝首饰行业协 会。从那时起, 上海的贵金属交易就已经有了自己的 行规（Sun and Nie, 2008）。老风祥（图 15）是最 初的九家银楼之一, 可能也是最有知名度的一家。老 凤祥成立于 1848 年, 到 1949 年, 它已经在上海开办 了三家连锁店。1952年, 政府买下了这几家店, 直 到现在老凤祥还是国有企业。老风祥几经浮沉而屹立 不倒, 现在已经是中国第二大珠宝零售企业, 在全国 范围内拥有2，300家零售店。

其他银楼大多分布在中国的东部。虽然他们中的 大多数在中日战争（1937-1945）和文化大革命中消 失了, 有一些还是幸存了下来并且尝试在新的珠宝首 饰市场中再创辉煌。银楼为中国现代珠宝首饰行业的 发展做了铺垫。

文化大革命。经历了多年的战争以及1966年到
1976年的文化大革命之后，中国终于有机会发展现 代化的经济了。这是中国珠宝首饰行业的新纪元, 这 30 年可以简单的分为四个阶段。

恢复期（1976-1989）。在文化大革命这一动荡 时期, 国家实行了一系列强制的措施, 珠宝首饰和其 他奢侈品禁止进入市场。1982年, 政府对珠宝首饰 行业的限制令终于解除了。1986年, 政府向市场投 入了100吨黄金用于首饰加工。在这之后, 由国家控 制近30年的珠宝行业终于可以独立发展了（Zhang, 2008)。

新的珠宝首饰企业和老的品牌一起合作开拓市 场，但是受中国经济发展的限制以及人们缺少可支配 性的收入，销售情况并不理想。数据显示1980年全 国仅有 10 家黄金首饰加工企业，从业人数为 10,000 人（Zhang, 2008）。那时多数商店仅经营金饰。消 费者几乎没有珠宝首饰的知识, 因此多数人购买的态 度是有什么就买什么, 将购买金饰品作为抵御通货膨 胀的手段。由于市场流通量有限, 黄金往往供不应 求。而零售店以国有企业为主, 私人企业非常少（Qiu et al., 2002)。

图 15. 老风翔是旧时银楼的代表, 其成立于1848年。这张 照片向您展示了老凤翔上海老店的外观。照片由上海老凤 翔提供。

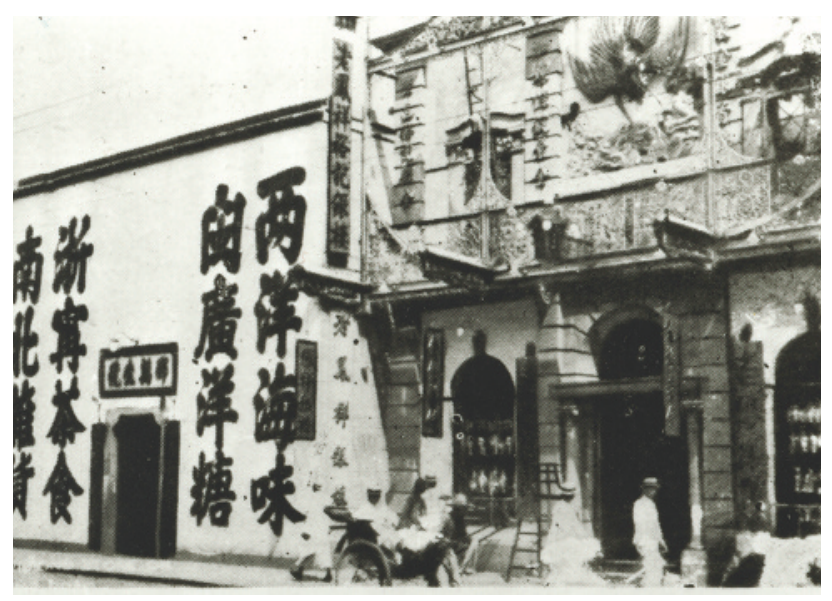


活跃期（1990-2000）。在二十世纪最后的十年 里, 中国珠宝首饰行业实现了飞跃式的发展。20世纪 90年代，成立了很多国有珠宝企业。这些企业除了为 人才培养和技术发展投入了大量的资金，还与国外以 及国有的大型百货公司合作。一些国外的珠宝企业首 次进入中国市场，戴比尔斯在上海成立了中国第一 家钻石推广中心。香港最成功的四个品牌（周大福、 周生生、谢瑞麟和六福）也进入了中国内地市场（图 16）。到20世纪90年代，珠宝企业已经发展到大约 20, 000 家, 从业人数达到了三百万（Gemmological Association of China, 2013）。1990年，珠宝行 业的销售总额为 20 亿元（3亿美元）。到2000年, 这一数字已经增长到 890 亿元（150亿美元）（China Economic Net, 2012）。中国珠宝首饰行业发展最快 的时期就是20世纪90年代（表3），现在的很多企业 都是那一时期成立的。

因为戴比尔斯的推广，中国的消费者开始接受钻 石。一些消费者甚至对钻石的品质要求过高。例如, 有的消费者买一颗10分的钻石，却坚持一定要 $G$ 色和 VVS的净度（Qiu et al.,2002）。中等和低质量的红 蓝宝石也从国际市场进口到中国。镶嵌类珠宝首饰也 在市场上获得了一席之地, 但是消费者对宝石的了 解还是非常有限。20世纪90年代铂金也在中国开始 流行。1994年, 中国铂金消费仅占世界市场总量的 $1 \%$ 。到 1998年，这一数字上升到 23\%，中国已成为 世界第二大铂金消费国（Zhang, 2008）。

从20世纪90年代到 21 世纪，国有百货公司仍然 是珠宝首饰销售的主要渠道。一些百货公司通过销售 珠宝首饰在竞争中存活了下来; 北京的菜市口百货公 司就是一个著名的例子。虽然已经不是一家百货公司 了, 但从1989年到2012年, 菜百公司蝉联北京市黄 金首饰销量第一。现在菜百也创立了自己的品牌。北 京的国华商场是另一个成功的范例。与菜市口百货公 司采取了相似的策略，国华商场现在是北京领先的铂 金首饰零售商。

稳定期（2000-2008）。21世纪，中国国内的珠 宝首饰行业进入了一个稳定增长的时期。2001年,

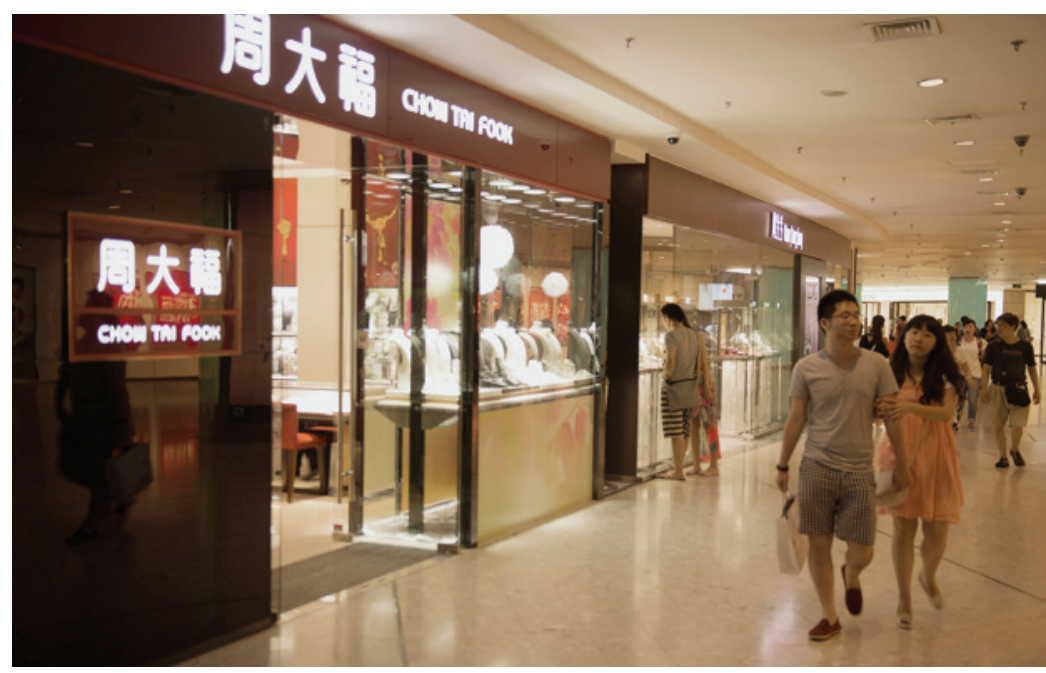

图16. 在疮㾂城市的购物中心里周大福珠宝零售店随处可见。 照片由Eric Welch拍摄。

中国成为了铂金首饰消费最多的国家。2007年，黄 金消费量达到363吨（图 17），仅次于印度（Zhang, 2008）。随着这些数字的增长，中国的珠宝首饰市 场和消费者也更加成熟。行业发展的重点从数量转变 到了质量。适应不了竞争的企业遭到了淘汰。到 2000年, 珠宝商们意识到了品牌的重要性, 并开始 通过推广企业文化和历史来进行产品的宣传。消费者 也开始关注设计而不仅仅是材料本身的价值了。

表3. 中国从1990 到 2012 年的珠宝销售情况.

\begin{tabular}{ccc}
\hline 年份 & 销售总值 (十亿元) & 增长率 $(\%)$ \\
\hline 1990 & 2 & \\
1993 & 24.1 & 1,105 \\
2000 & 89 & 269.3 \\
2001 & 96.5 & 8.4 \\
2002 & 105.3 & 9.1 \\
2005 & 140 & 15 \\
2006 & 160 & 14.29 \\
2007 & 160 & 0 \\
2008 & 180 & 12.5 \\
2009 & 220 & 22.22 \\
2010 & 250 & 13.64 \\
2011 & 380 & 40 \\
2012 & 454 & 19.2 \\
\hline
\end{tabular}

数据来自中国经济网 (2012) 和张栋 (2008). 


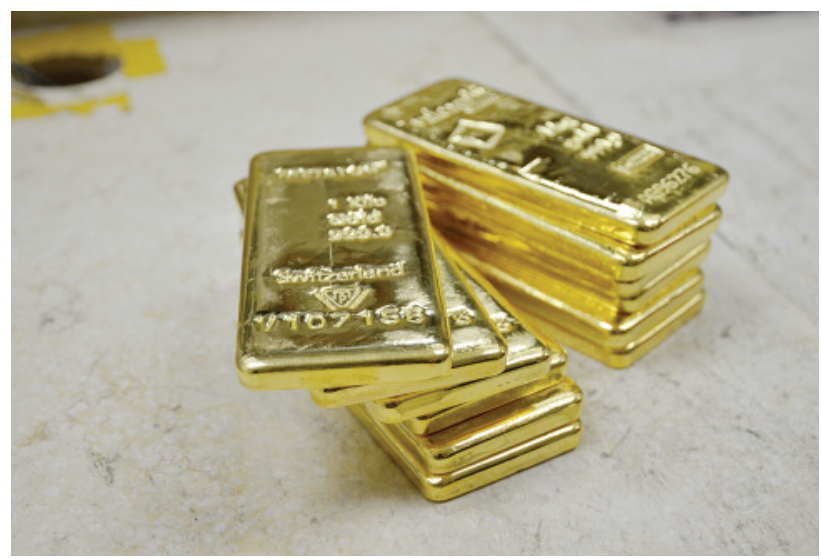

图 19. 上海黄金交易所的成立是中国为黄金投资和首饰用金 而开放黄金市场的划时代标志。金条由周大生珠宝提供。照 片由《中国宝石》提供。

税收改革。从1978年开始, 中国为适应本国经济的 迅速发展, 进行了几次税收系统改革。大规模的社会 主义经济体制改革始于1994年, 相伴而来的是自由 市场经济政策的革新。2003以来, 中国又实施了一 系列与收入、财产和出口税相关的改革。例如 2012 年, 中国共有25个税收类别。中央财政收入更加依赖 于消费类税收, 相比传统的所得税对个人储蓄的损害 更小 (Institute for Research on the Economics of Taxation, 2010)。

中国的税收立法权是高度集中的。只有国务院可 以制定和修订国家税收法律和政策。国家税务总局负 责征收税务。地方政府可在一定条件下调整部分税 率, 但总体而言, 地方政府增加、减免税收, 或改变 主要税率的权利范围极为有限。

与美国不同的是，中国对消费税的依赖性要大于 所得税。增值税（VAT）占了企业和个人税收的很大 一部分; 这也体现在珠宝企业中。根据国家税务总局 网站发布的信息，基本税率分为两种：13\%和 17\%。 尽管对于外国公司而言出口给中国如有色宝石类的珠 宝产品会被征收比较高的税率, 但黄金和钻石的进口 因相关交易所的建立变得透明和简化。

黄金交易所。上海黄金交易所（SGE）由中国人民银 行组建于 2002 年10月, 作为一个非营利组织, 旨在
管理国内的黄金交易（图19）。它为黄金交易提供设 施和监管，制定国内贵金属价格，同时也连接了中国 和国际市场。SGE还与检测机构合作, 对黄金进行质 量监督和认证。

交易所的成立主要归因于几个事件。2000年, 政府实行五年经济计划, 其中包括对外开放黄金市 场（Skoyles, 2013a）。一年后，中国人民银行取消 了对国家黄金市场的垄断。不久后，黄金报价每周都 得到公布, 通过调整黄金现货价格, 反映自由市场价 格。这为SGE的建立铺平了道路 (Skoyles, 2013a)。 结果是中国黄金的价格根据国际市场的价格而定。

仅2011年一年, 中国最大的银行 (中国工商银 行ICBC）已有超过一百万的黄金储蓄账户，上海黄金 期货交易所经办的黄金期货合约达 1.44 亿。中国对黄 金最大的需求仍来自于珠宝, 2011 年其增长率为 $27.87 \%$ ，是2010年的5.45倍（上海黄金交易所, 2011）。这种高速增长主要是由于个人收入的增加, 同时也是防止对冲膨胀的需要; 后者促使投资者在价 格上升时购入黄金。到2012年, 中国的黄金消费总 量达到832.18吨（图20）, SGE也成为了世界最大的 实物黄金交易中心。

图20. 中国的黄金需求一直稳步增长。改编自新浪网 (2013)。

\section{中国的黄金需求，2002-2012}

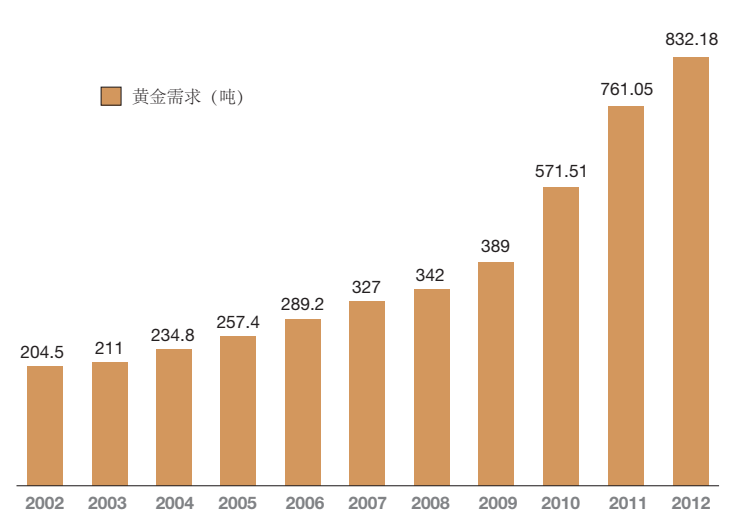




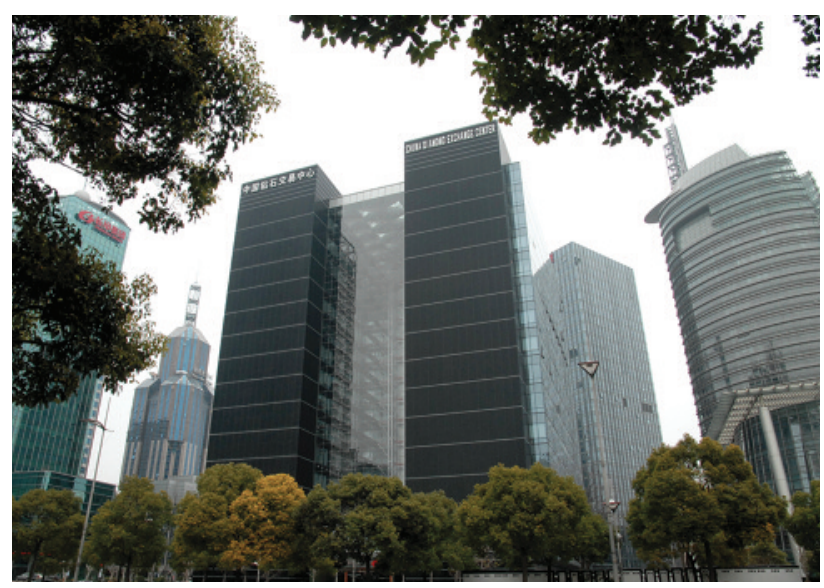

图21. 上海钻石交易所就坐落在这座建筑中, 现在它已经成 为世界上最重要的钻石交易所之一。所有合法进口的钻石 都是从这里进入中国的。交易所为钻石的进口提供一站式 的服务。照片由上海钻石交易所提供。

2013年上半年, SGE向中国国内市场供应了 1098吨黄金, 占全球总供应量的25\%以上（Skoyles, 2013a）。SGE在中国34个城市设有41个货仓用于黄 金的储存和交付。黄金实物在交易成功三天后交付给 会员。

钻石交易所。2000年10月，上海钻石交易所 （SDE）成立。其所在地中国钻石交易中心（图21）, 也常被作为SDE的代称。在此之前, 进口钻石的关 税、增值税和营业税总额非常高，达到35\%至40\%。 得益于交易所的成立，现在钻石的税收政策十分优惠 （表4）。尽管中国对所有进口商品征收17\%的增值 税, 但对抛光钻石则退还 $13 \%$ 税费, 净增值税仅为 $4 \%$ 。如果钻石原石在中国加工后在国内市场销售,

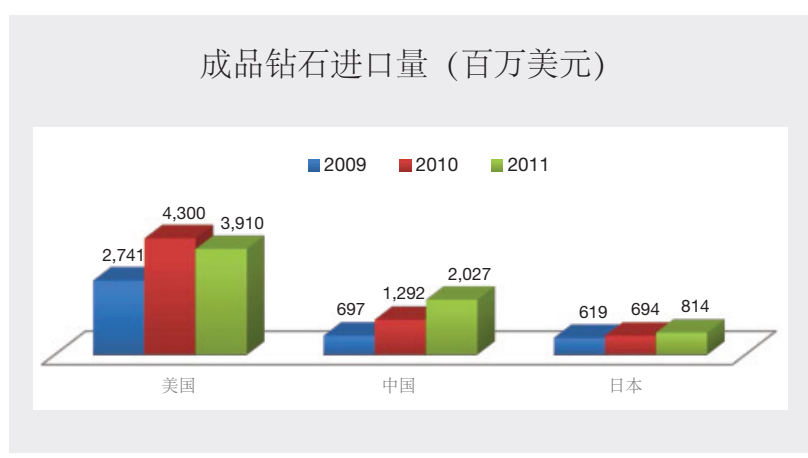

图22. 中国对钻石进口量的增长远远超过了其他重要钻石消 费市场。改编自上海钻石交易所资料（2013）

其增值税与进口抛光钻石相同。如果钻石原石在中国 加工后回销至出口国, 则免收增值税。这些改革为遏 制逃税的走私钻石进入中国起到了重要作用。

中国钻石交易中心内设鉴定实验室、钻石商办公 室、政府机构和运输服务机构, 是中国钻石进出口的 中心。钻石交易所控制了所有钻石原石的进出口, 但 并不包括钻石首饰。交易所于 2004 年加入了世界钻 石交易所联盟, 并于2008年在上海主办了第33届世 界钻石大会。

钻石交易所极大地推动了中国钻石产业的发展。 据官方统计，在其成立以前，钻石年进口额约为 1 百 万美元。到 2011 年, 钻石年进口额已超过 50 亿美 元, 其中进口到中国大陆的约为20亿美元（图22） 。据钻石交易所统计, 受全球经济环境影响, 2012 年中国钻石进口额下降10\%, 但预计2013年会有所 回升。

表4. 中国钻石税收政策.

\begin{tabular}{l|c|c|c}
\hline & 2002年6月前 & 2002年6月-2006年6月 & 2006年7月至今 \\
\hline 关税 & 毛坏: 3\%; 成品 9\% & \multicolumn{2}{|c}{$0 \%$} \\
\hline 增值税 & \multicolumn{2}{|c|}{$17 \%$} & 毛坏: $0 \%$; 成品: $4 \%$ \\
\hline 消费税 & \multicolumn{2}{|c|}{$10 \%$ 进口环节 } & $5 \%$ 零售环节 \\
\hline
\end{tabular}

数据来自上海钻石交易所 (2013) 
中国钻石交易中心是中国大陆唯一合法的钻石进 出口区域。由中央政府建立, 旨在通过简化钻石进出 口程序使交易更加便捷。根据中国法律, 所有进口钻 石必须通过交易所进入征税流程（图23）。所有进口 钻石需经中国海关报关和密封, 否则将被视为非法走 私。

同样，进口钻石原石必须在进入中国前经过查 验。钻石须附有金伯利进程证书, 并由CDEC下属相 关部门检查和登记。证书通过检查后, 原石方可进入 国内市场销售。中国继2013年出任金伯利进程代理 主席国后, 又在2014年成为了主席国, 由中国国家 质检总局的一位官员任主席。

中国钻石交易中心是一个完全开放的平台，向世 界各地的钻石商敞开大门。它共有350个会员, 其中 $67 \%$ 来自以色列、比利时、英国、法国、美国、日本、
非洲国家和其他海外地区。会员企业中，有114 个来 自中国大陆, 62个来自香港, 50个来自印度, 32 个 来自以色列, 以及23个来自比利时; 其余 69 个来自 其他国家。

中国钻石交易联合管理办公室。钻石交易联合管 理办公室（DAC）成立于2000年4月, 由商务部授 权，负责监管钻石贸易。DAC及其他政府机构共同控 制着国家日常的钻石进出口贸易，以及中国钻石交易 中心内的钻石交易活动。

DAC 的职能包括管理和统计分析国家钻石进出口 贸易，审核交易是否符合钻石交易所规范，同时监督 钻石交易所的运作。在交易所内, DAC与其他政府工 作人员合作，批准并监督外商投资企业在中国的商业 活动, 参与制定钻石的进出口政策, 并为钻石交易所 及所有国内外钻石企业提供服务。

\section{进口钻石在中国国内市场销售过程中的税收}

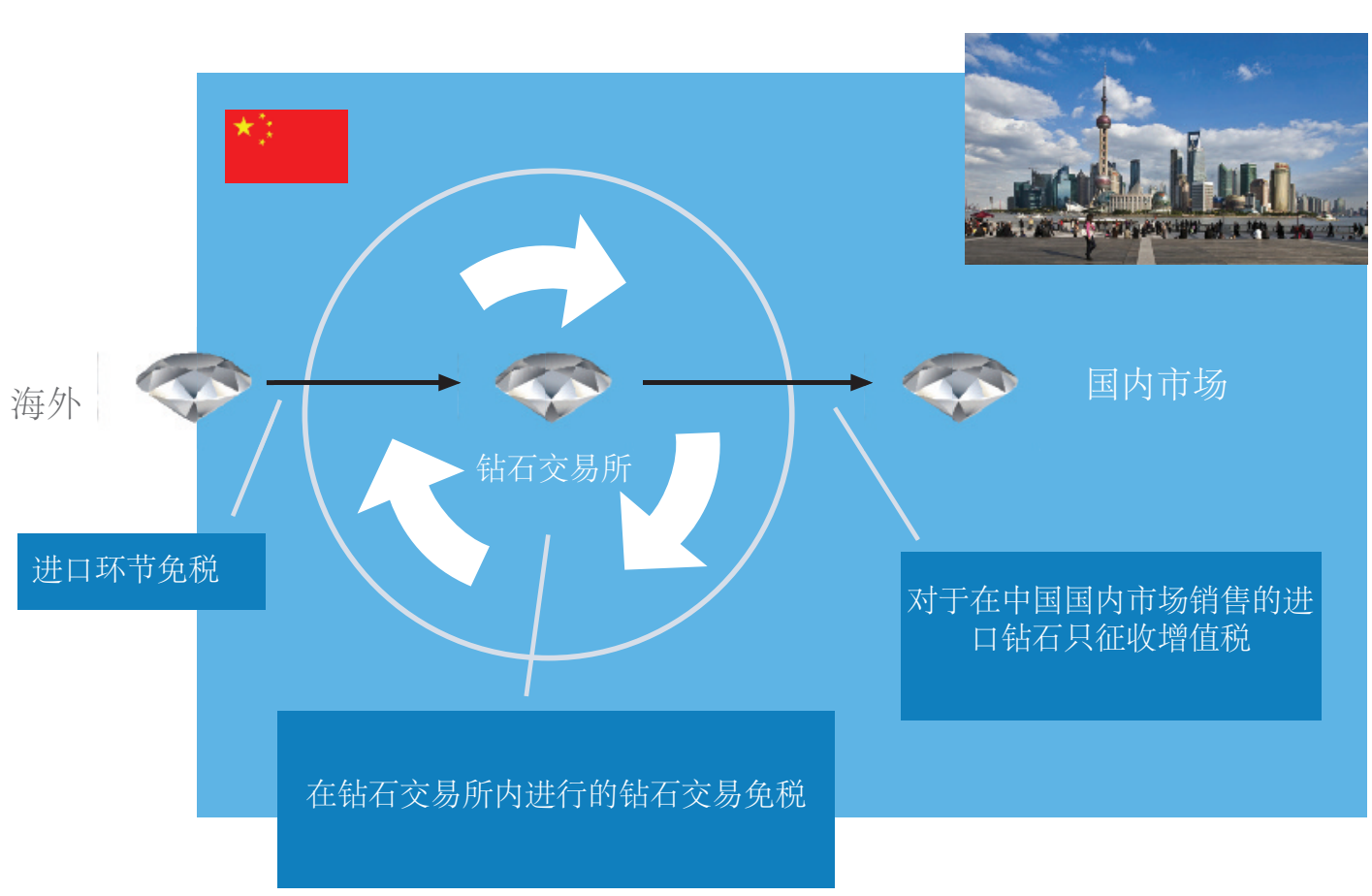

图23. 钻石一旦离开钻交所进入国内市场就要被征收税款。改编自上海钻石交易所（2007） 
彩色宝石。与钻石和黄金拥有独立的交易中心和 特殊的税收政策不同的是, 彩色宝石和彩色宝石首饰 的税率与其他奢侈品相同。由于中国没有太多的彩色 宝石资源，彩宝市场主要依赖进口产品。关税、增值 税和消费税都由中央政府控制, 地方政府征收商业 税。进口彩色宝石的关税税率为 $8 \%$, 零售商和批发 商还要另付 $10 \%$ 的营业税。镶嵌彩色宝石首饰的增值 税则更是高达 $17.5 \%$ ，营业税为 $5 \%$ 。也就是说，对于 彩色宝石，珠宝零售商或批发商需要支付大约 $40 \%$ 的 总税率, 这大大推高了此类产品的价格。例如, 一条 卡地亚LOVE手链2013年在香港的售价为38555元 ( 约6000美元), 而在深圳的价格则为47300元（ 8000 美元）。其间相差约为 $35.7 \%$, 这一定程度上是 由中国对彩色宝石首饰征收的高税率造成的。

中央政府对不同的行业采取不同的税收政策; 因 此, 改变需要更长的时间。一些特殊的政策可以帮助 降低税率。例如, 钻石交易所的成立使钻石贸易享有 特殊税率, 有效地降低了中央政府的征税额。彩宝行 业如果建立起类似的组织机构, 或许能起到同样的作 用。此外, 中国与其他国家间的进出口互惠政策以及 特殊贸易区的建立也可帮助减少关税。最难改变的 是增值税, 因为中国中央政府的财政收入主要依赖 于此。而仅为一个行业进行改革则更为困难 (Qiu, 2013）。地方的税收政策往往较中央政府更为灵活, 主要取决于当地政府对珠宝行业发展的态度。

\section{实验室标准}

为规范宝石和首饰贸易、保护消费者权益, 以现 代宝石学知识为基础的行业标准相应出台。在过去的 30年中, 结合西方的经验和国内宝石学家们的研究, 中国制定了一系列实验室标准。

其中三个最重要的标准是, 珠宝玉石名称标准（ GB/T 16552-2010), 珠宝玉石鉴定标准(GB/T 16553-2010), 以及钻石分级标准(GB/T 165542010)。国内所有实验室均遵循这些标准。这些标准 于1996年首次发布, 2010年推出修订版本, 并于 2011 年2月起开始实施（“2010 edition of the three..., ”2011）。此外, 还有针对贵金属的标准。

作为世界最大的翡翠消费国, 中国多年来一直在 尝试制定翡翠分级的国家标准。但这是一个非常困难 的过程, 因为翡翠的外观变化范围很大, 如透明度、 颜色分布及质地。因此, 每一块翡翠都是独一无二 的, 其评估在很大程度上依靠个人经验, 使用商业术 语。2009年, 国家质量监督检验检疫总局、中国国 家标准化管理委员会发布了翡翠分级的国家标准, GB/T23885-2009。这项标准主要针对绿色翡翠（图 24），但同样适用于无色、紫色及红色-棕色材料。 四个评价因素为颜色、透明度、质地和净度。宝石学 家还会在证书上对翡翠的雕工予以评价。现行的标准 用字母代表不同级别, 同时也注明对应的商业术语, 以便消费者更好地将实验室报告与自己的翡翠相对 应。这项标准的建立, 得到了NGTC 实验室和高端翡 翠商的共同支持。

中国同时也是世界最大的人工养殖珍珠产出国。 2002 年, 针对海水和淡水养殖珍珠的分级标准出台 （GB/T 18781-2002），这一标准旨在规范养殖珍 珠的命名、评价因素、分析手段和产品标记方式。

图24. 绿色翡翠的价格近年疯狂晃升, 不同品质或级别的翡 翠在价格上可以是天壤之别。照片由Eric Welch拍摄。珠 宝由昭仪翠屋提供。

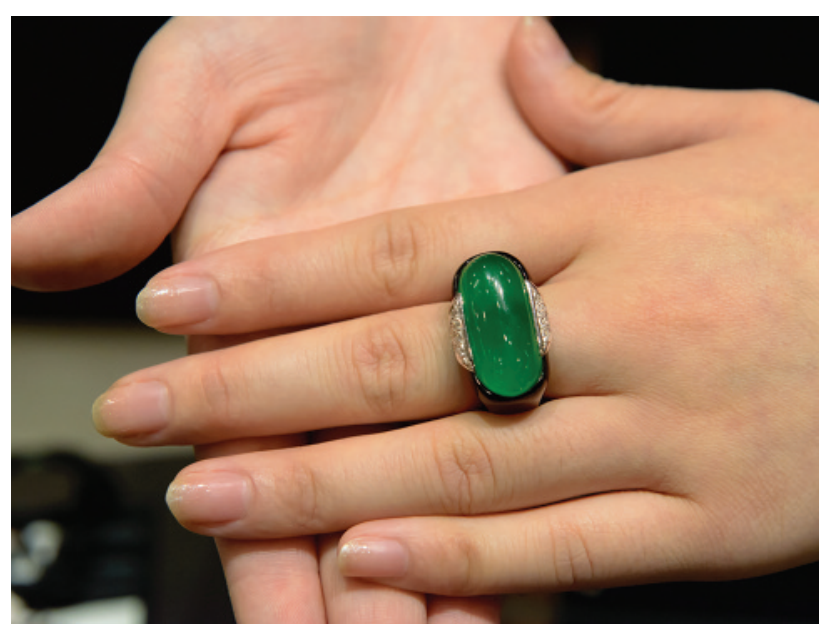

Gems \& Gemology

SPRING 2014 
其他彩色宝石品种也同样在中国拥有巨大的市 场, 如红宝石、蓝宝石、红碧公及坦桑石。消费者 和宝石学家都希望颁布和实施更多的针对宝石鉴定 与评估的国家标准, 为购买和鉴定这些宝石材料提 供更好的指导。

\section{专业教育与培训}

1989年，全国仅有2万人从事珠宝行业。三十 年后，该行业从业者达到三百万。与此同时，珠宝 培训与教育的格局也发生了变化。珠宝行业需要掌 握采矿、生产、销售和管理技能的人才。同时, 宝 石学、设计及工程方面的专家也是行业发展必不可 少的。对比其他国家，中国拥有较为独特的珠宝培 训和教育系统（图25）。这一系统有两个主要组成 部分。

职业培训。在中国成立现代培训机构以前, 珠 宝技能是通过师傅传授给学徒的。这种一对一的培 训已有数千年的历史，直至近些年国家对外开放。 但这种教育方式对于大范围员工培训并不十分有效。 现代证书培训课程最初在西方取得了成功。中国引 进了这些西方课程。

1989年，中国地质大学（武汉）与英国宝石 协会合作成立了联合教育中心，并开设了中国第 一个FGA课程（Yang, 2013）培训班。此后, 更 多的国外宝石学及钻石学证书培训项目在中国启 动。例如钻石高级议会（HRD）1993年在上海开 设了教育中心，一年后 Gem-A 的培训中心在武汉 成立。美国宝石学院1998年在北京开设了第一期 研究宝石学家 (graduate gemologist) 的中文课 程。这些课程每年共培养约300名学生（Yang, 2013）。

随着越来越多的宝石学家接受培训, 中国开始发 展自己的证书课程。不同的机构, 包括大学、国家宝 石首饰技术中心和宝石协会都可以提供专业证书。例

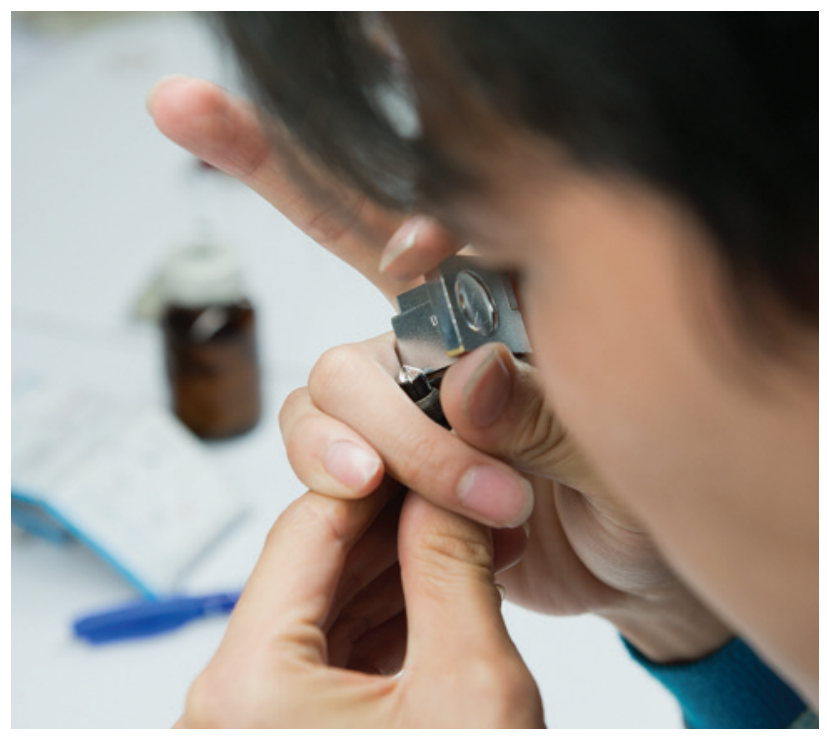

图25. 宝石学教育和培训对于中国珠宝业未来的发展至关重 要。照片由Eric Welch拍摄, 场景由周大福珠宝提供。

如, 中国地质大学（武汉）开办的GIC证书课程, 在 2012年有 4000 人报名（Yang, 2013）。这些课程 的培训内容包括宝石学、加工、设计、销售和管理。 国内外教育机构间的竞争，促进了专业培训课程的 发展。许多国内实验室开设了面向珠宝公司、银行 和保险公司高层管理人员的高端课程以帮助他们更 好的了解珠宝贸易与投资趋势。国家级的实验室和 协会也与国内领先的珠宝品牌的销售精英合作为店 员进行销售管理培训。一些珠宝咨询师甚至为高端 投资者和收藏家提供一对一的培训。

学位课程。中国另外一个特色的培训体系是宝 石学专业的高等教育。自 80 年代中期开始, 一些学 校就开设宝石学的大专教育。成立于1992年的中国 地质大学 (武汉) 的珠宝学院便是首个在中央政府 注册的此类院校。1998年, 教育部正式将宝石学列 为国内大学的一个专业 (Yang, 2013)，学生可以在 获得本科学位后继续攻读硕士和博士。这个专业的 教育内容也逐渐拓展到包括珠宝设计、首饰加工及 珠宝商贸在内的其他领域。2009年, 中国地质大学 
(武汉) 成为了首个招收珠宝设计专业研究生的大 学。

在珠宝行业内, 为保证竞争中的人才优势, 许多 企业高薪聘请人才, 并为员工进行特殊培训。平洲妈 祖翡翠公司董事长表示, 其公司的许多翡翠雕刻师年 薪超过百万。广东省一家大型钻石切割工厂的负责人 介绍，该工厂员工的薪水近几年来一直以每年 $15 \%$ 左 右的速度增长。

\section{珠宝加工}

中国作为世界最重要的加工中心也是全球领先的 珠宝制造国。大部分珠宝生产集中在广东省。超过 2000 家珠宝公司坐落于深圳，每年产值达80亿美元。 约占中国实际珠宝产量的70\% ( “Shenzhen steps up role..., " 2012）。中国也从主要依赖低成本的生 产模式转变到依靠高技能劳动力和尖端技术的生产模

图26. 中国的宝石切磨和首饰加工产业需要大量进口的彩色 宝石原石来满足生产的需求。照片由Andrew Lucas 拍摄, 场景由Enzo提供。

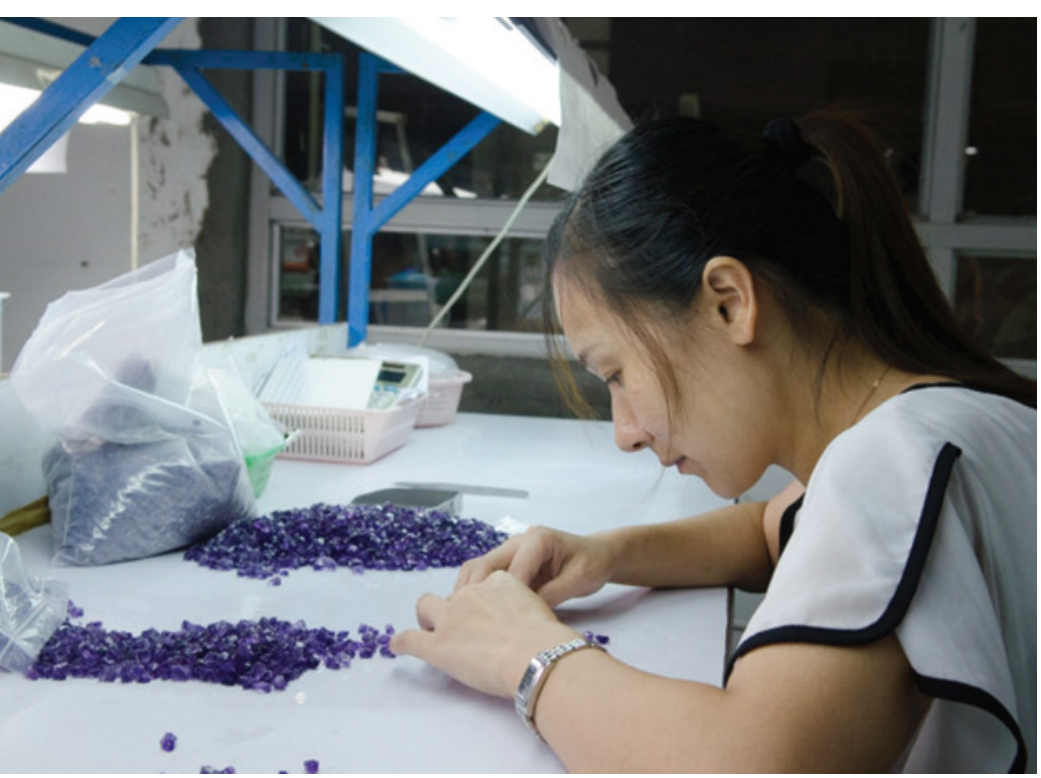

式上, 例如钻石的激光切割, 计算机辅助切割设计, 彩宝的高精度机械切割以及铂金的真空铸造。行业投 资的重点放在了提高技术和员工技能水平上。中国珠 宝制造业也面临多重挑战，如成本上升、消费成熟、 产业链的复杂性以及全球经济环境的不稳定性。其中 最大的障碍是原石材料的供应。

中国宝石加工业以加工彩色宝石原石著名（图 26）。2013年的图森珠宝展上，几位美国珠宝商在 接受采访时表示, 要在原石采购上与中国竞争, 难度 很大（美国宝石学院，2013）。许多珠宝商纷纷表 示, 中国切割工厂和珠宝制造商给出的价格是他们无 法竞争的。

为满足市场对于彩色宝石日益增长的需求, 中国 开始在非洲国家投资以保证充足的原材料供应。南非 基础设施建设是其中最大的投资项目之一，也被列入 了2001年开始的五年计划中（Ashok, 2013）。这些 非洲国家中有一些出产钻石。津巴布韦, 是一个重要 的潜在钻石产出国, 自2011年起, 中国的商品、服 务和资金不断涌入津巴布韦进行钻石交易（Ashok, 2013），截至目前，这一战略非常成功。在2006年 到2011年间, 全球钻石原石供应量下滑3\%, 而中国 原石进口量却增加了 20\%，进口总额增加了 55\% Ashok, 2013）。随着全球原石竞争的加剧, 钻石采 购仍将是一个挑战。

中国曾是主要的低成本制造中心, 现在面临着诸 多挑战, 如成本上升、消费者不断成熟以及需求与产 业链的复杂性和全球经济的不稳定性。国家现在主要 依靠高技能的员工和尖端技术以及高质量产品这些优 势帮助解决其制造业所面临的大部分问题。

\section{国内珠宝首饰市场}

中国一直是全球珠宝行业加工和出口的领先力 量, 而且预计其国内市场的发展潜力最大。尽管工人 工资的上涨对中国的生产环节而言是一个挑战，但却 为其珠宝零售业创造了巨大商机。 


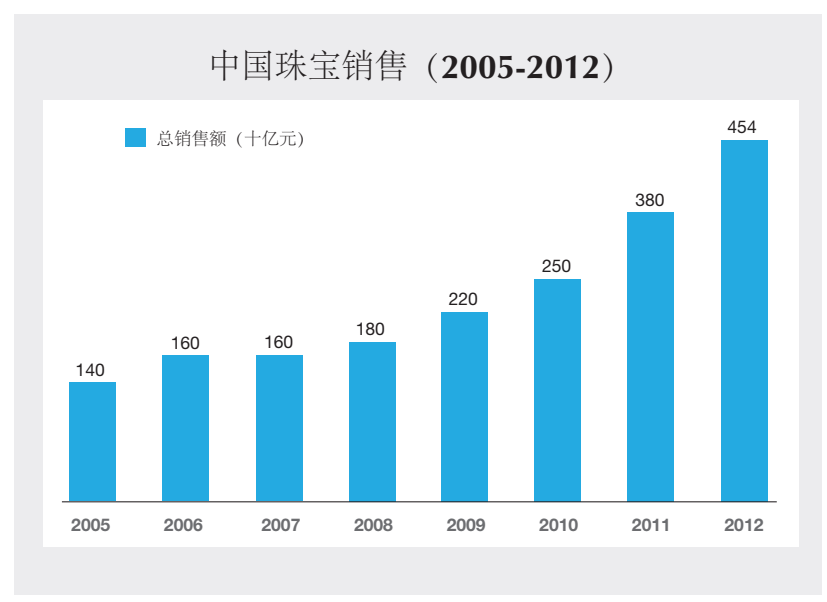

图27. 从2005年开始中国的珠宝销售就开始大踏步的增 长, 很多年份都实现了两位数的增长。数据来自中国经济 网 (2012)。

国内首饰市场。中国目前是世界第二大首饰市 场。尽管经历了繁荣时期和增速缓慢的时期, 但总体 增长显著（图27）。

2013年四月金价下跌时，中国消费者抓住机会， 低价购入黄金，这也包括黄金首饰。当月的珠宝零售 总额为303亿元（50亿美元），同比增长72.2\%（ HKTDC Research, 2013）。

尽管在过去几年里, 中国国内珠宝消费显著增长,

图28. 虽然中国的人均珠宝消费相较于其他发达国家还比较 低, 但这一数字正在迅速增长, 这预示着中国珠宝市场的 惊人潜力。数据来自中国经济网（2012）。

\section{人均珠宝消费状况 (2009)}
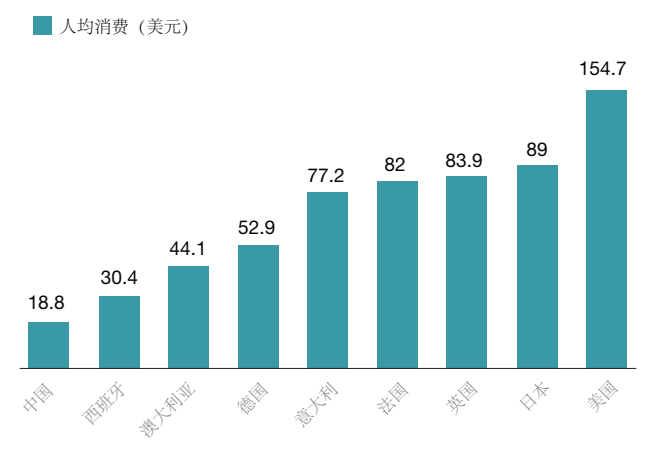

中国的黄金、铂金和钻石消费 (2012)

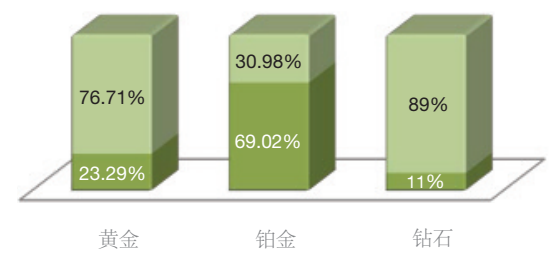

中国

其他国家

图29. 中国消费了世界上相当数量的黄金、铂金和钻石。数 据来自“Diamond giant De Beers...,” (2012); Johnson Matthey (2013); and China National Gold Group Corporation (2013).

但未来仍有发展空间。与其他许多国际市场相比, 中 国人均珠宝消费仍相对较低（图28）。自2009年, 中国和美国的珠宝消费均大幅增长，其中，中国的人 均消费翻倍。然而, Diamond Index Group的常务董 事Michael Huang表示, 中国的珠宝消费仍远远落后 于主要发达国家（Krawitz, 2013）。据估计, 中国 人均珠宝消费约 44 美元，而日本为 91 美元，美国为 242美元（Krawitz, 2013）。

黄金首饰。如图29所示, 黄金首饰仍是中国市 场的主导产品。到2012年，中国累计消费518.8吨黄 金首饰，是全球发展最快的黄金首饰市场; 超过 $75 \%$ 的中国城市女性拥有一件以上的黄金首饰（世界黄金 协会，2013）。三分之二的中国女性将购买黄金首 饰更多地视为一种投资。仅2013年就有6600万中国 新娘希望在婚礼上收到黄金首饰（世界黄金协会, 2013）。显然，黄金对于中国人而言具有独特的情 感价值。

在美国，钻石首饰在整体珠宝消费中所占比例更 高。但在中国, 随着新消费阶层的成长以及非一线城 市的发展, 国内钻石和珠宝首饰市场继续发展, 市场 随之变得更加多样化。对比中国与印度、美国的珠宝 消费类别就可以发现这一点（图30）。 


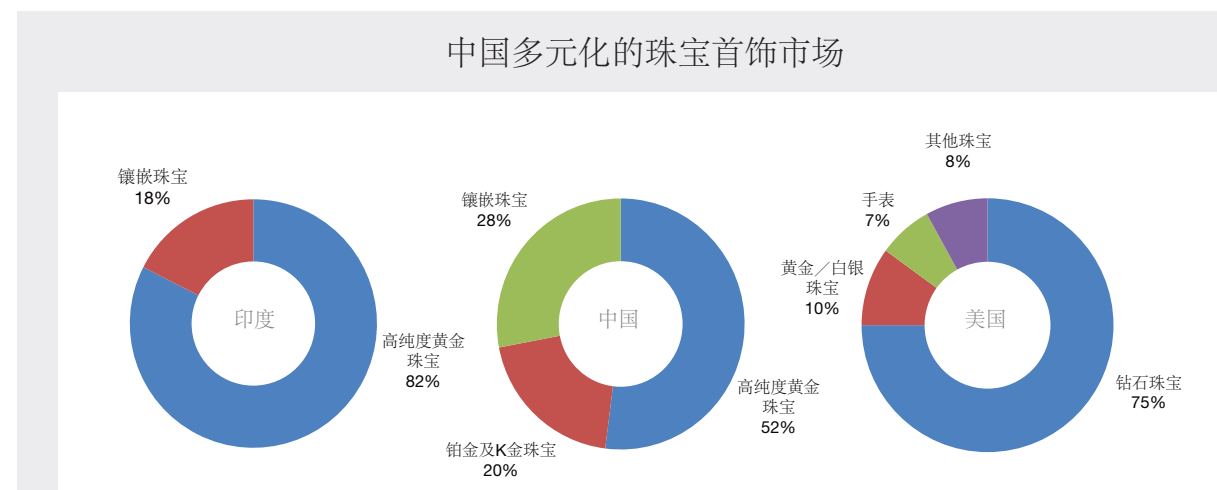

图30. 中国的珠宝首饰市场 相比于印度更加多元化, 印 度珠宝市场以黄金为主。数 据来自“2012年中国珠宝进 出口统计数据”（2013）。

中国消费者对 $24 \mathrm{~K}$ 黄金首饰有强大的需求，原 因在于其内在价值和中国人对纯度的偏爱。2 4 K 黄 金占中国黄金销售的 $80 \%$ 以上（世界黄金协会, 2013）。

黄金已进入镶嵌珠宝市场, 出现在婚庆产品和西 方设计师的作品中。2008年, 世界黄金协会与中国 设计师及制造商合作推出了K-Gold品牌, 主打18K黄 金首饰。这一系列产品的宗旨在于激励新锐设计师并 吸引年轻消费者, 并将传统与创新相结合。世界黄金 协会还推出了两个黄金首饰系列的广告大赛。“爱的 印记(Sign of Love)” 和“爱的密码(Code of Love)” 这两个系列突出体现了以黄金作为首选定情信物的传 统。

到2013年, 中国已取代印度成为了世界上最大的 黄金消费国（世界黄金协会，2013）。当年，世界黄 金协会珠宝和市场总裁戴维・拉姆（David Lamb） 在其官网的采访中表示, 中国的二、三线城市将陆续 开设更多的珠宝店。这反映出随着经济发展, 这些城 市消费需求在不断上涨。在采访中他也提出首饰流 行趋势将重新回归到纯金首饰, 而非18K及其他 $\mathrm{K}$ 金 首饰。

铂金首饰。中国是全球最大的铂金消费国，据 世界铂金协会统计，2012年中国的铂金消费占到全 球的68\%。在2012年的一次演讲中，世界铂金协会 （PGI）的CEO高伟政（James Courage）表示，自 1997 年起，PGI共向中国市场投入1.5亿资金用于推 广贵金属，这项投资在铂金产业收到了43亿回报。高
伟政还补充道，首饰占到全球铂金消费的 $31 \%$ 。中 国的铂金首饰消费在 2011 年上涨了 $16 \%$ ，作为首 饰消费的铂金达195万蓝司（Johnson Matthey， 2013）。

在中国市场, 通常由女性决定何时购买珠宝及购 买哪一类珠宝, 无论是买给自己还是情侣间互赠。中 国销售的大部分铂金首饰并不镶嵌宝石，但在如今的 婚庆珠宝市场, 镶宝石尤其是镶钻石铂金饰品的需求 正在增加。PGI的市场调查表明, 铂金的纯白色和耐 久性象征了纯真与终生的承诺, 与中国婚庆文化不谋 而合。（Stone Xu, pers. comm., 2013）。

高伟政先生介绍了他在中国见到的情况, 许多铂 金首饰工厂拥有上千名员工，每年生产首饰达上万吨 （Johnson Matthey，2013）。在中国，大型的珠宝 制造商经常有巨大的展厅以供零售商前来挑选货品。 事实上, 笔者在中国参观的展厅规模远远超过在其他 任何国家所见的, 货品堆满仓库, 买家论斤采购。铂 金首饰的制造商也是同样情况。

和其他零售市场相同，中国的珠宝销售从独立的 零售店, 转移至百货公司内的珠宝柜台及专业珠宝购 物中心。这一现象在二、三线城市尤为突出。百货公 司一般将玲琅满目的珠宝陈列在客流量最大的一层。 据PGI统计, 铂金饰品一般占珠宝类产品的 10\%至 20\%，高于其在其他国家市场中所占比例。

二、三线城市消费者通常购买 $24 \mathrm{~K}$ 黄金首饰, 但 也希望向一线城市消费者靠拢。据PGI统计, 在上海 
等国际化都市，所销售的婚戒 $60 \%$ 为铂金。随着二、 三线城市市民可支配收入的增加, PGI预测这些城 市的结婚率以及婚戒中铂金所占比例将会提高。研 究还表明, 在大城市, 中国消费者开始青睐西方较 盛行的三环婚戒。这也有可能成为二、三线城市的 发展趋势。

银饰品。中国是世界最大的银饰制造国。2011 年工业用银占中国银生产量的 $56 \%$, 而珠宝制造业 用银占 34\%（Silver Institute，2012）。随着银饰 品的风格突破了传统的婚庆和庆生首饰的设计, 国 内银饰品消费急剧上升。2006年后, 二、三线城市 的年轻消费者开始推崇银饰产品, 大部分推广也主 要针对这些城市。近年来, 农村地区消费者将银饰 作为白色黄金和铂金的低成本的替代品。镀铑的银 饰品外观与铂金相似, 也开始流行。国内制造商复 制黄金生产线用于生产银饰产品, 为巨大的中国消 费市场, 特别是入门级的消费者提供了低成本的替 代品。

钻石首饰。中国现在是仅次于美国的第二大钻 石市场。在过去的五年里, 钻石首饰从占中国珠宝 零售市场的四分之一增长为三分之一（“All that glitters...,"2013）。在国际市场中, 中国和印度预 计将主导钻石饰品市场的成长（Bain \& Company, 2013）。这一增长很大程度上是由于西方以钻石 作为订婚戒指和结婚戒指的传统开始被中国人接 受。在中国, 每年约有1300万新娘（“All that glitters..., ” 2013）。黄金结婚戒圈逐渐变为镶钻石 戒指。据蒂凡尼的亚太和日本地区总裁 Stephane Lafay介绍, 在过去 20 年里, 中国城市居民购买钻石 婚戒的比例已从 $1 \%$ 增长到 $50 \%$ 以上（"All that glitters..., ”2013）。另一方面, 中国许多主营24K黄 金首饰的大型珠宝公司, 例如周大福, 也开始进军 钻石首饰市场。

面对2011年钻石市场的波动, 周大福董事总经

\section{钻石珠宝零售额}

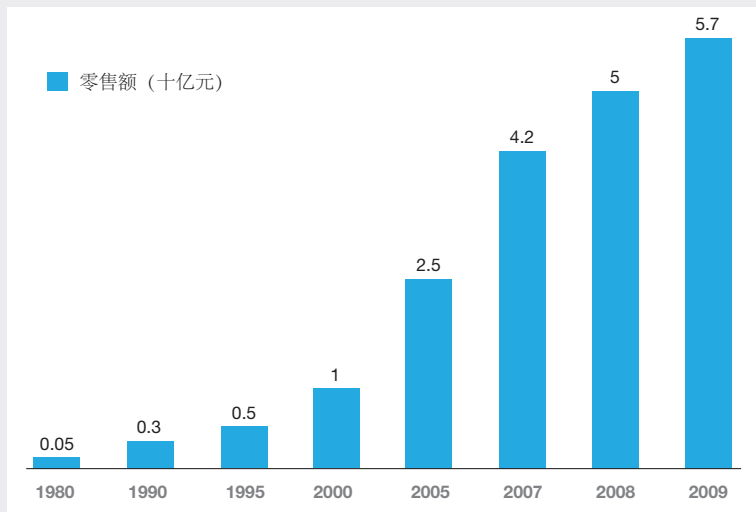

图31. 在过去的三十多年中中国的钻石销售取得了显著的增 长（数据来自上海钻石交易所, 2013)

理黄绍基表示, 中国珠宝市场发展是周期性的, 尤 其体现在中央政府及其政策发生变化的时候（

Krawitz, 2013）。钻石作为真爱、永恒和纯洁的象 征, 如今的人均消费量还相对较低, 发展将是未来 的必然趋势。受西方影响, 将钻石首饰作为特殊场 合的礼物已成为一种流行趋势, 加之钻石时尚首饰 的发展, 业内许多人士纷纷看好中国的钻石行业。

2012年，必拓力拓公司发布了一份全球市场研 究公司益普索的调查报告，报告显示中国消费者越 来越青睐价格适中、时尚多变的钻石首饰（“Rio Tinto research confirms strong potential $\cdots$, 2012）。中国的钻石消费在全球消费中所占的比例 远远低于黄金和铂金，其市场仍有巨大的成长空间 （图31）。

彩色宝石。近几年来, 尤其自2010年起, 中国 珠宝消费拓展到彩色宝石领域。一线城市的彩色宝 石零售量最高, 二线城市紧随其后（表5）。随着可 支配收入的提高, 三线和四线城市的彩色宝石零售 额也将大幅上涨。 


\begin{tabular}{cllllc} 
表5. 中国彩色宝石零售额 (十亿元). & & & \\
\hline & 2007 & 2008 & 2009 & 2010 & 2011 \\
\hline 零售总额 & 4.3 & 5.4 & 7.2 & 9.6 & 13.4 \\
一线城市 & 1.8 & 2.2 & 3.0 & 4.0 & 5.6 \\
二线城市 & 1.6 & 2.0 & 2.7 & 3.7 & 5.1 \\
三线城市 & 0.6 & 0.8 & 1.0 & 1.4 & 1.9 \\
其他地区 & 0.3 & 0.4 & 0.5 & 0.6 & 0.7 \\
\hline
\end{tabular}

数据来自卢礼航 (2013).

2013年图森珠宝展上, 许多珠宝商反映, 美国 客户销量出现反弹并有大批中国买家加入（美国宝石 学院, 2013）。他们还指出价格大幅上涨主要是由 于中国消费者的加入。事实上，几位展商表示他们需 要为此补充库存。一位美国彩色宝石商说到, “我曾 前往一个宝石矿采购原石, 但却得知一位中国买家已 经到过那里并购买了他们的原石。当我半年后再到那 里时, 那位中国买家已经买下了整座矿。”

参加2013年图森珠宝展的珠宝商还反映, 与过 去几年相比, 中国买家感兴趣的彩色宝石品种更多 了。红色是中国传统流行色, 红宝石和红碧贫 (图

图 32 . 中国已经成为世界各地产出的红色碧等的主要消费 国, 比如像照片中的这些产自尼日利亚的红碧坌。照片由 Robert Weldon拍摄。

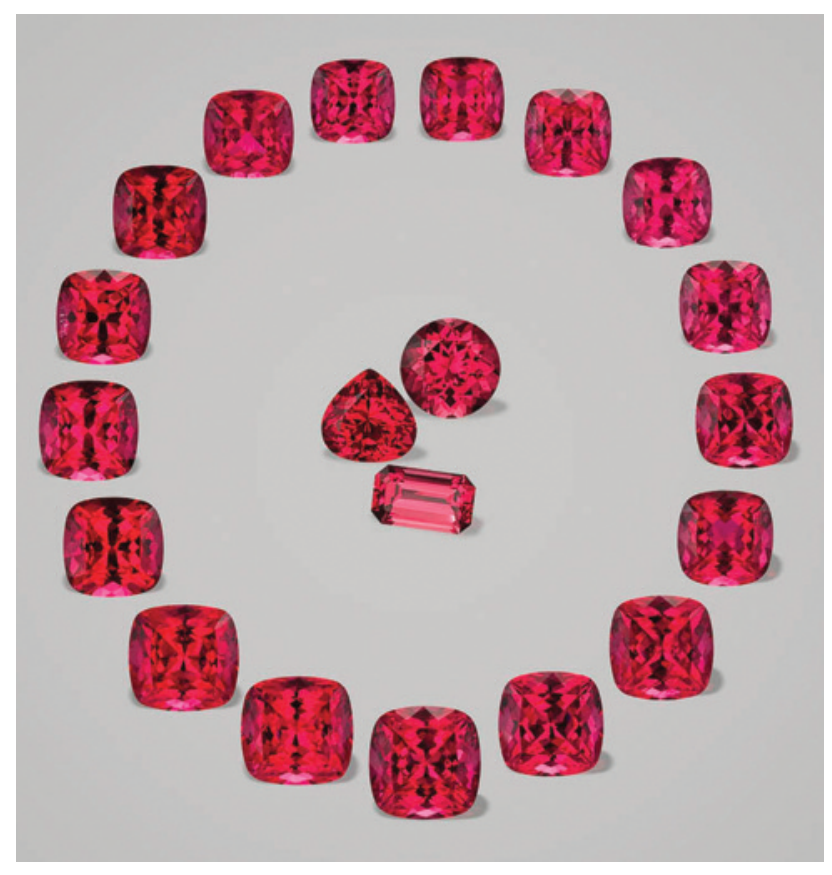

32）已流行了很多年。许多珠宝商共同促成了这两 种宝石在中国市场价格的飞涨。2013年9月26日, 佳士得在上海举办了其在中国大陆的首场拍卖会, 一条红宝石钻石项链拍出了340万的全场最高竞拍 价 ( “Ruby necklace tops Christie’s first China auction,”2013）。根据笔者的观察和来自行业内的 反馈, 其他红色和粉色宝石, 例如尖晶石、石榴石、 粉水晶和红玛瑙也开始受到中国消费者的追捧。

其他颜色的彩色宝石也同样有需求。随着红碧筀 价格上涨，其他颜色的碧筀首饰也更加流行（“Tourmaline grips Chinese collectors,” 2013)。蓝色和绿 色碧坌, 以及其他蓝色宝石, 如蓝宝石、海蓝宝石、 蓝色托帕石, 甚至一些知名度较低的宝石, 如矽线石 猫眼, 也开始在中国市场占有一席之地 ( “Blue and green gems on the rise $\cdots, ” 2012)$ 。蓝色至紫色的 坦桑石尤其受欢迎。近期，拥有2200家国内门店的 大型零售企业周大生, 成为了TanzaniteOne的 “裸石 零售看货商”（Max, 2013），这表明中国市场已向 非传统彩色宝石敞开大门。中国消费者已经意识到彩 色宝石品种有很多选择, 同时他们可以在不同价位找 到适合他们的产品。

Enzo, LJ国际公司的零售分公司最近获得了莫桑 比克一个含铜碧筀矿的采矿权（图33）。该公司希望 通过其在中国大陆的250家零售店, 将这种独特而无 比鲜艳的宝石推广到国内市场 (Lorenzo Yi, pers. comm., 2013）。推广方式包括广告、贸易媒介以及 明星代言等。

中国彩色宝石行业, 无论对于出口还是国内销售 来说所面临的最大挑战是原材料的采购 (Wilson Yuan, pers. comm. 2013）。许多宝石品种在原石采 


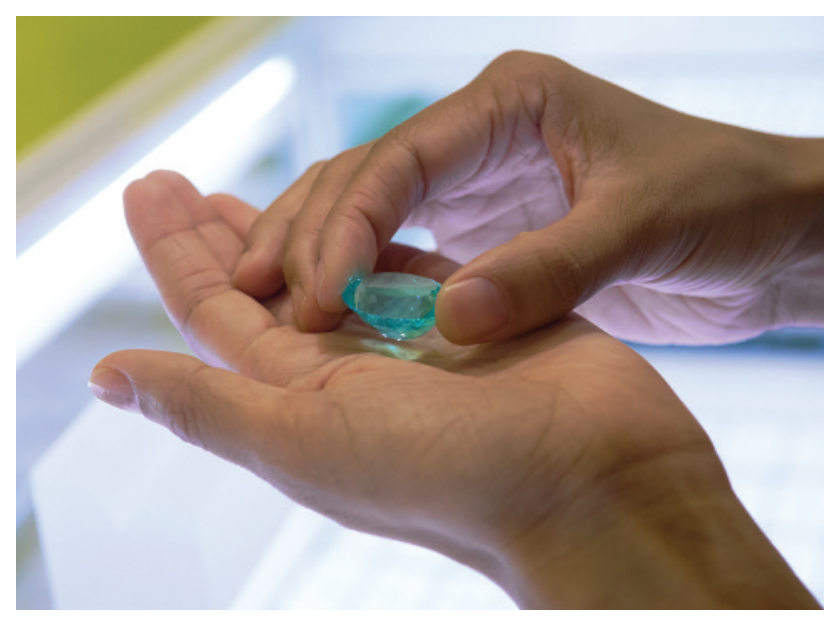

图 33 . 像这颗在 2013 年 9 月香港珠宝展上被中国买家 买走的产自莫桑比克的含铜的蓝绿色碧筀越来越受到中国 消费者的青睐, 需求也日趋增大。照片由Andrew Lucas拍 摄, 宝石由Enzo提供。

购上都存在激烈的竞争, 特别是高质量的原材料, 其 他珠宝加工中心如印度、泰国和斯里兰卡也存在同样 的问题。随着中国消费需求的上涨, 彩色宝石原石价格 也在豛风升。其价格上涨也对全球市场产生积极影响。 例如, 一些以前不具经济开采价值的宝石矿（如巴西 的红碧筀矿）现在就可以进行开采。

翡翠。尽管翡翠在中国的历史不及和田玉久远, 但仍是中国最流行的宝石材料。广东省玉石协会表 示, 从90年代末到现在, 已有数千吨翡翠原石由广州 口岸进口到中国（Tingxin Li, pers. comm., 2013）。 翡翠在当地进行雕刻或加工, 使得广东成为了国内翡 翠加工和销售的中心。广东省平洲地区是中国最大的 翡翠原石市场, 也被称为翡翠手镯之乡（图34）。当 地每年举办 20 多场拍卖会, 吸引了全国的批发商和 零售商。四会地区则汇集了来自莆田和南阳的雕刻 师, 这些雕刻师将木雕和石雕的技法和理念运用于翡 翠中。

另一个重要的进口地区位于云南省的中缅边界, 是 中国最早的翡翠进口地区。2007年, 云南有约6千家 翡翠公司; 五年后, 这一数量激增至2.1万（Tingxin Li, pers. comm., 2013)。主要的市场集中于腾冲、盈 江和瑞丽。

从2000年到2009年, 翡翠价格以平均每年20\%

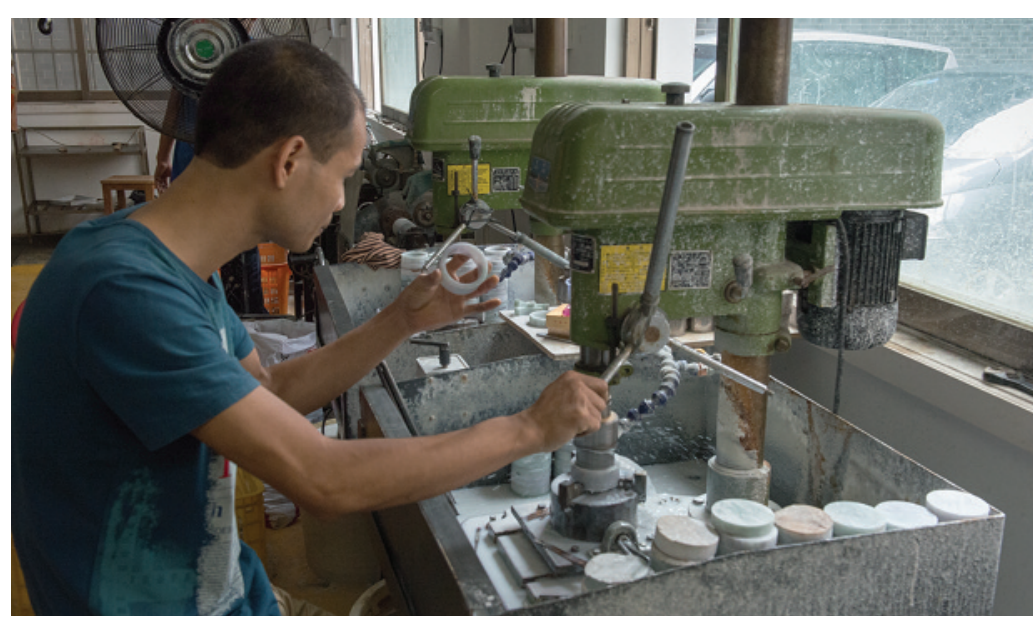

图 34 . 广州境内的平洲市是翡翠手镯之乡。这位工人师傅 正在用机器去除手镯的镯芯。照片由Eric Welch 拍摄。

的速度上涨。到了2011年和2012年, 这一比例已增 加至每年30\%以上（中国工业信息网，2013）。缅 甸作为中国翡翠的主要供应国，希望控制其出口并发 展自己整条产业链业务, 然而中国对高端翡翠的需求 仍在持续增长。一些翡翠商不得不利用其外汇储备来 应对原石的短缺。在2013年6月的缅甸翡翠公盘上, 原石价格飞涨。只有不到 1 万件原石可供购买（对比 于上一次公盘的原石数量为2-3万)，其价格翻了 310倍（Chen, 2013）。来自云南和广东的贸易专家 指出: 高质量翡翠的零售价格增长比例与原石基本一 致; 而中低档翡翠价格基本未受影响。价格攀升是中 国消费者不希望看到的，消费者并不愿花大价钱购买 低质量材料（Tingxin Li, pers. comm., 2013）。即便 高端翡翠产品价格居于高位, 中国的收藏者和投资者 （不论在国内还是全球范围内）对其仍有需求。

\section{进口和出口}

从珠宝进口国及其进口额（图35，左）的统计情 况可明显看出, 欧盟与其名牌奢侈品珠宝产品对中国 市场的重要性。如果将中国消费者出国旅游时购买的 欧洲珠宝加入进来, 进口额则更为可观。进口商品的 另一部分是来自印度的低端产品。

从中国的珠宝出口贸易统计数据可以看出“一国 两制”政策在管理中国大陆与香港中所起的重要作 
中国 2012 年珠宝首饰进出口情况, 按国别划分
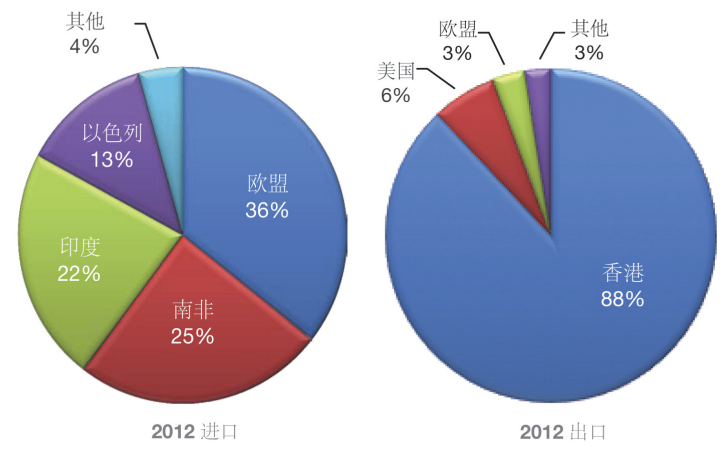

图 35 . 左: 欧盟是中国珠宝首饰的主要进口商, 这可能是 由于其拥有众多的奢侈品牌造成的。右：中国出口到香港 的珠宝首饰所占的巨大比例表明这个城市是中国首饰通往 世界市场的重要通道。数据来自“2012年中国珠宝首饰进 出口统计数据” (2013)。

用。香港是中国的一部分, 同时作为自由贸易区, 拥 有得天独厚的地理优势, 成为了中国的出口中心。在 2012年, 中国88\%的珠宝出口到香港（图35, 右）, 大部分销往国际市场。

钻石首饰在中国进口珠宝中所占价值比例最高, 2012年达71\%（图36, 左）。部分原因是钻石交易 所使进口渠道便捷高效, 增值税的减免也降低了钻石 在国内的价格，以及产品本身的价值。如图36所示 右）, 中国是国际珠宝市场的主要供应国; 最大的出 口类别是首饰用具和贵金属首饰。在整体出口比例 中, 钻石和宝石首饰仍有较大的增长空间, 同时彩色 宝石和养殖珍珠的进出口贸易, 也在持续增长。

\section{总结}

中国是目前世界第二大珠宝消费国。在过去的 30 年间, 中国经济展现出显著增长和抗压性, 平均年增
中国 2012 年珠宝首饰进出口情况, 按种类划分
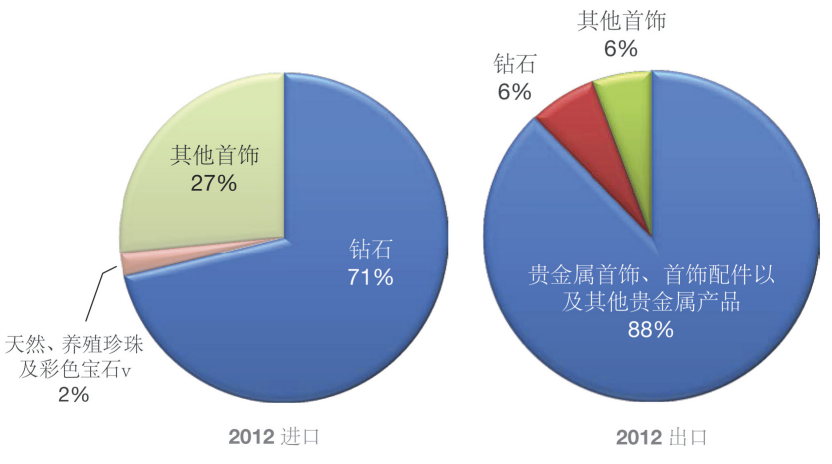

图 36 . 左: 钻石首饰是中国进口量最大的珠宝。右：贵金 属首饰及首饰配件占中国珠宝业出口量的最大比例。数据 来自“2012年中国珠宝首饰进出口统计数据” (2013)。

长率约为 $10 \%$ 。尽管其经济增长在未来几年预计将 有所放缓，中国仍有可能在下一个十年赶超美国。 2011 年提出的最新的五年计划将重心放在可持续性 增长和发展国内消费上。下个十年, 大批中国公民将 集中到城市地区, 欠发达的内陆城市将成为发展重 点。随着可自由支配收入的增长, 国内商品消费特别 是珠宝等奢侈品消费也将增长, 这将在三线和四线城 市体现得尤为突出。同时, 中国的第二代消费者, 也 就是80年代中期以后出生的年轻人, 具有国际视野并 乐于接受西方风格的产品。他们对于未来的信心是促 进可自由支配开支的一个积极信号。

中国消费者比较看重品牌和质量，但不同消费者 对品牌的喜好不同。例如, 非一线城市居民倾向于购 买有明显品牌标志的产品, 而国际化沿海城市的购买 者则更喜欢低调朴素的产品。中国奢侈品消费者比欧 美国家消费者更年轻, 且已将奢侈品视为必需品。此 外, 光棍节的双十一促销等电子商务活动取得成功,

表6. 中国对宝石、天然及养殖珍珠的进出口统计数据（十亿美元).

\begin{tabular}{lccccccc}
\hline & 2005 & 2006 & 2007 & 2008 & 2009 & 2010 & 2011 \\
\hline 进口 & 3.5 & 4.6 & 6.3 & 7.5 & 6.5 & 10.8 & 14.9 \\
出口 & 5.5 & 6.9 & 8.1 & 8.5 & 7.5 & 12.5 & 27.5 \\
\hline
\end{tabular}

数据来源：联合国商品贸易统计数据库 (2013). 
未来中国消费的持续增长将是必然趋势。随着中国重 新向国际市场开放, 香港的珠宝贸易充分利用了广东 省的低成本劳动力和新建的自由贸易区等优势。“国两制”政策使香港在1997年回归以后仍保持自由 市场, 这刺激了中国出口的快速增长。在中国珠宝产 品通过香港走出去的同时, 国际市场的珠宝产品也开 始进入国内市场。黄金交易所的成立促成了进出口政 策的改革, 包括税收政策的修订, 加速了国内珠宝产 业的发展。劳动力成本的上涨对中国珠宝加工业是一 个挑战, 但技术改革和面向高端市场的发展战略使其 仍保持着在全球市场中的竞争力。

与美国相比, 中国人均珠宝消费额较低, 但一直 在飞速上涨。铂金在相对较短时间内取得成功，充分 展示了这个国家对新产品的接受能力。钻石首饰在中 国一直很受欢迎，尤其在婚庆市场，钻石时尚首饰将 是未来新的增长领域。各类彩色宝石在国内市场销售 并受到关注。国际市场中的彩色宝石价格, 如红宝 石、红碧等和其他颜色碧等, 受到了中国消费者的 影响。其他宝石的销售, 如坦桑石等, 也已取得了较 大的增长, 然而传统的翡翠仍然极为流行。

作为全球制造业的领军者, 中国也在不断发展和 扩大国内的珠宝市场。尽管国家仍面临诸多挑战, 如 贫富不均、环境问题和官僚体制的障碍, 其蓬勃发展 的珠宝首饰行业仍将拥有更加光明的未来。

关于作者

许泰女士是美国宝石学院《宝石与宝石学》杂志 的技术编辑, Andrew Lucas 先生是美国宝石学院的 实践宝石学负责人。丘志力先生是中山大学地球科学 系教授及宝玉石研究鉴定中心主任。李牧先生是上海 钻石交易联合管理办公室副主任。于庆媛女士是广东 省地质矿产公司宝石应用研究所所长。两位翻译贾晓 丹和林默青是美国宝石学院香港分部的宝石鉴定师。

致谢

作者在这里要感谢以下珠宝专业人士为我们 2013

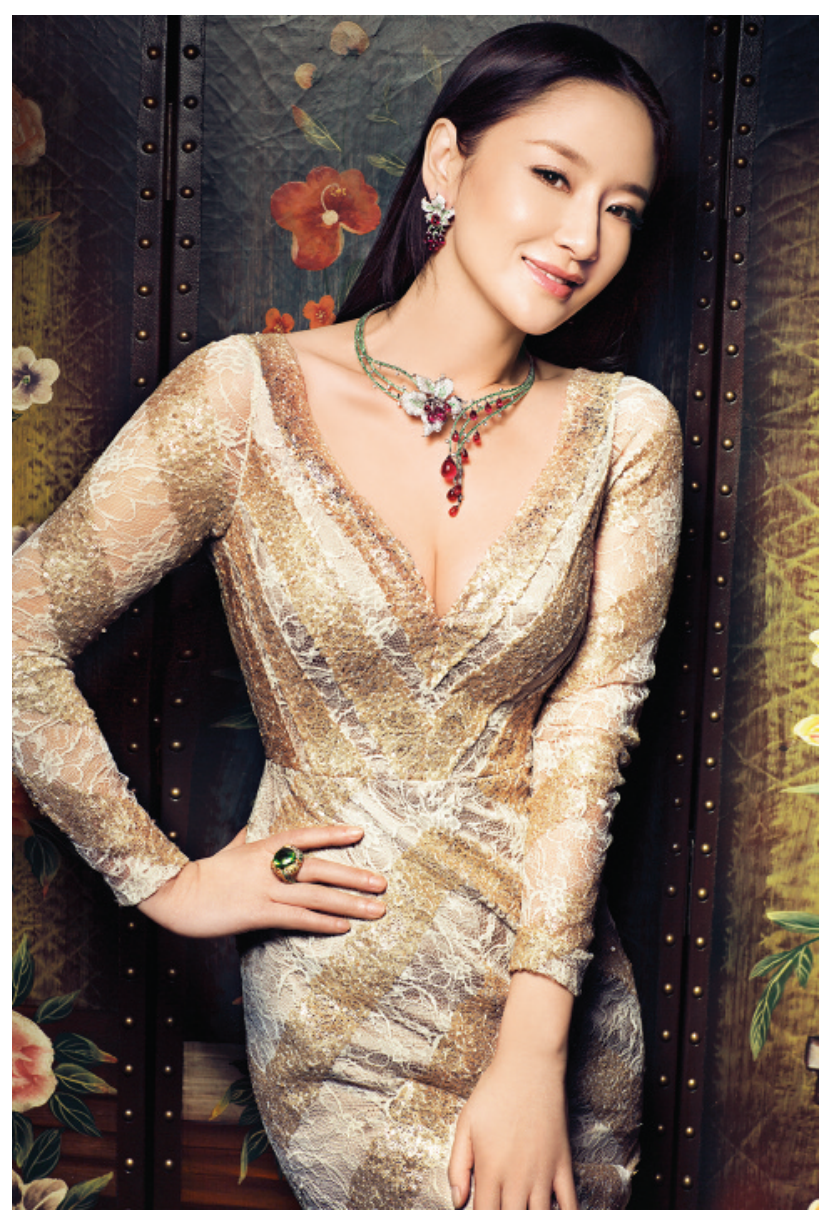

图 37 . 如同其他类别的珠宝首饰一样, 彩色宝石首饰近 来在中国越来越流行, 这个趋势还将继续延续下去。首饰 由Enzo提供, 照片由欧阳拍摄。照片由《中国宝石》提供。

年的中国之行提供的大力支持: 国际有色宝石联合会 的袁健㭉先生和张雪莉女士; 国家珠宝玉石质量监督 检验中心深圳实验室的丁汀主任和中国宝玉石协会副 秘书长沙拿利先生; 广东省珠宝玉石及贵金属检测中 心的郭清宏主任和曹姝敏副站长; 华东理工大学的郭 守国教授和郎小波同学; 昭仪翠屋的高露和蒋维薇经 理; 中国地质大学 (北京) 珠宝学院的余晓艳教授和 熊见竹同学。作者同时还要感谢为我们提供拍摄场 地, 接受我们采访的各个珠宝公司、首饰加工厂、政 府相关部门及独立珠宝设计师们, 大家为我们提供了 宝贵的行业发展信息。如果没有以上珠宝专业人士们 的鼎力相助, 作者是无法完成这次调研的。 


\section{参考文献}

2010 edition of the three promulgated national standards have been approved (2012) China Jeweler. Sept. 21, http://www.chinajeweler. com/zhubaohangye/xingyezixun/guanlizhongxingonggao/ detail_2012_09/21/349715_0.shtml [in Chinese].

2012 import and export statistics of the Chinese jewelry industry (2013) Jewelry Life, http://www.jewelrylife.org/Archive1409.html.

Adam S. (2010) China may surpass U.S. by 2020 in "super cycle," Standard Chartered says. Bloomberg News, Nov. 14, http://www.bloomberg.com/news/2010-11-15/china-may-surpass-u-s-by-2020-in-super-cycle-standard-chartered-says.html.

All that glitters: Diamonds outshine gold for Chinese brides (2013) CNBC, Sept. 16; http://www.cnbc.com/id/101038830.

Ashok T.N. (2013) Indian diamond industry losing sparkle. Hindu Business Line, Jan. 29, http://www.thehindubusinessline. com/opinion/indian-diamond-industry-losing-sparkle/article 4357705.ece.

Atsmon Y., Magni M., Jin A., Li L. (2012) From mass to mainstream: Keeping pace with China's rapidly changing consumers. McKinsey and Company Consumer \&) Shopper Insights, http://csi.mckinsey.com/Home/Knowledge_by_region/Asia/ China/2012 Annual Chinese Consumer Survey.aspx.

Atsmon Y., Magni M., Liu, M., Li L. (2011) 2011 Annual Chinese consumer study: The new frontiers of growth. McKinsey $e^{+}$ Company Consumer 4 Shopper Insights, http://csi.mckinsey. com/Home/Knowledge_by_region/Asia/China/2011_ Annual Chinese Consumer Survey.aspx.

Bain \& Company (2012) 2012 China luxury study: Bain point of view, https://www.fccihk.com/files/dpt_image/5_committees/ Luxury\%20Committee/121212-2012\%20Luxury\%20study_ Media\%20release.pdf.

— (2013) Global diamond report 2013, http://www.bain.com/ Images/BAIN_REPORT_The_global_diamond_report_2013.pdf.

Barnett S. (2013) China: Fastest growing consumer market in the world. IMF Direct, Dec. 2, http://blog-imfdirect.imf.org/2013/ 12/02/china-fastest-growing-consumer-market-in-the-world.

Barton D., Chen Y., Jin A. (2013) Mapping China's middle class. McKinsey Quarterly, http://www.mckinsey.com/insights/ consumer_and_retail/mapping_chinas_middle_class.

Blue and green gems on the rise, says manufacturer (2012) Jewellery News Asia, Sept. 22, http://www.jewellerynewsasia.com/ ensearch/search_result/5833/Blue-and-green-gems-on-therise-says-manufacturer.html.

Central Intelligence Agency (2013) World Factbook 2013-14: China. https://www.cia.gov/library/publications/the-worldfactbook/geos/ch.html.

Chen J.H. (2013) Jadeite market of Myanmar. China Gems, No. 4, pp. 170-171 [in Chinese].

China Diamond Exchange Center. (2013) China Diamond Exchange Center Compendium 2013. Diamond Administration of China, Shanghai, pp. 1-39.

China Economic Net (2012) The 2011 investigation of Chinese jewelry industry and predictions, Jan. 16, http://intl.ce.cn/qqss/ 201201/16/t20120116_23004368.shtml [in Chinese].

China Industrial Information Network (2013) Analysis of the development of Chinese jadeite industry, May 28, http://ind.chyxx. com/201305/205990.html [in Chinese].

China National Gold Group Corporation (2013) 10 main gold consumption countries consumed about $62.06 \%$ of world gold production in 2012, http://chinagoldgroup.com/n4/n64/ c25210/content.html [in Chinese].

Communist Party of China (2011) The Twelfth Five-Year Plan for National Economic and Social Development of the People's Republic of China. The Central People's Government of the People's Republic of China, Nov. 4, http://www.gov.cn/ 2011lh/content_1825838.htm [in Chinese].

Courage J. (2012) Platinum jewellery in China. Speech given at
LBMA Precious Metals Conference, Hong Kong, Nov. 12, http://www.lbma.org.uk/assets/JamesCourage.pdf.

D'Arpizio C. (2012) 2012 Luxury goods worldwide market study (11th Edition). Bain and Company, http://www.ipmark.com/ pdf/lujo_2012.pdf.

Diamond giant De Beers: Chinese diamond demand is slowing (2012) Wall Street Horizons, September 22, http://wallstreetcn. com/node/18480 [in Chinese].

Diamond Administration of China. (2007). Bonded policy. http://www.dac.gov.cn./diamond/picnewinfo.aspx?id=26.

Dobbs R., Chen Y., Orr G., Manyika J., Chui M., Chang E. (2013) China's e-tail revolution, McKinsey Global Institute Report, March 2013, http://www.mckinsey.com/insights/asia-pacific/ china_e-tailing.

Fishman T.C. (2004) The Chinese century. New York Times, July 4, http://www.nytimes.com/2004/07/04/magazine/04CHINA. html.

Flaven G. (2013) The business of luxury and culture in China. Jing Daily, Nov. 14, http://www.jingdaily.com/chinas-luxurymarket-evolving-not-declining/39502/.

Fung Business Intelligence Centre (2013) Luxury market in China: Huge growth potential ahead, http://www.funggroup.com/eng/knowledge/research/china_dis_issue109.pdf. Gemmological Association of China (2013) 2012 Chinese Jewelry Industry Yearbook. Beijing: Geological Publishing House.

Gemological Institute of America (2013) An inside look at the 2013 Tucson shows. http://www.gia.edu/tucson2013-show.

HKTDC Research (2013) China's jewellery market, Aug. 6, http://china-trade-research.hktdc.com/business-news/article/ China-Consumer-Market/China-s-jewellery-market/ccm/en/ 1/1X3AYEP5/1X002MMK.htm.

Hurun Research Institute, Inc. (2013) The GroupM KnowledgeHurun wealth report 2013. http://img.hurun.net/hmec/2012 08-02/201208021120412790.pdf

Institute for Research on the Economics of Taxation (2010) Policy Bulletin No. 94: The tax system of China, Dec. 23, http://iret.org/ pub/BLTN-94.PDF.

International Monetary Fund (2013) World Economic Outlook: Hopes, Realities, Risks. Washington, DC: International Monetary Fund Publication Services. http://www.imf.org/external/ pubs/ft/weo/2013/01/pdf/text.pdf.

Johnson Matthey (2013) Platinum 2013. http://www.platinum. matthey.com/media/1614079/platinum_2013.pdf.

KPMG China (2011) China's 12th five-year plan: Overview. http://www.kpmg.com/cn/en/IssuesAndInsights/Articles Publications/Documents/China-12th-Five-Year-PlanOverview-201104.pdf.

Krawitz A. (2013) Chow Tai Fook, China \& the diamond industry. Rapaport Magazine, Aug. 16, http://www.diamonds.net/News/ NewsItem.aspx? ArticleID $=44272$.

Li J.J. (2013) Jade trade capital. Jade Street, Vol. 7, pp. 21-23 [in Chinese]

Lin Q. (2012) Shanghai diamond exchange and the Chinese diamond market. Gems \&) Jewelry Trade Association of China Annual Meeting Report, http://biz.ifeng.com/zhubaowang/ zhubaohangye/tebiezhuanti/2012baoxienianhui/hangyejigoufayan/ detail_2012_12/14/482946_0.shtml [in Chinese].

Lu L. (2013) Sustainable development, current situation, and future trend of China gemstone industry. Presented at the 15th International Colored Gemstone Association Congress, Changsha, China, http://www.gemstone.org/images/files/congress2013/ speaker/08Congress2013_Lu\%20Lihang.pdf [in Chinese].

Lui V., Kuo Y., Fung J., Walters J., Hsu H., Liao C. (2012) The Age of the Affluent: The Dynamics of China's Next Consumption Engine. Boston Consulting Group, http://www.bcg.com.cn/ export/sites/default/en/files/publications/reports_pdf/BCG_ The_Age of the Affluent_Nov_2012_ENG.pdf. 
Max D. (2013) Chow Tai Seng becomes TanzaniteOne sightholder. Idex Online News, September 16, http://www.idexonline. com/portal_FullNews.asp?id=38602.

Qiu Zh.L. (2013) The structure system and tax policy of China and the analysis of the development of colored gemstone industry. Presented at the 15th International Colored Gemstone Association Congress, Changsha, China, http://www.gemstone.org/ images/files/congress2013/speaker/07Congress2013_Qiu\%20Z hili.pdf [in Chinese].

Qiu Zh. L., Liang W. Zh., Gong Sh.W., Wang M., Lu H.F., Mai Zh.Q. (2002) Continuous development of jewelry sales in China [in Chinese], Journal of Gems and Gemmology, Vol.4, No.2, pp. 39-42.

Rare Investment (2013) Rare Investment predicted it: Chinese diamond consumer tsunami depleting world supply. http://www. rareinvestment.com/latest-news/rare-investment-predicted-itchinese-diamond-consumer-tsunami-depleting-world-supply/.

Rio Tinto research confirms strong potential for new diamond jewellery category in China (2012) Jewellery News Asia, May 24, http://www.jewellerynewsasia.com/en/search/search_result/45 16/Rio-Tinto-research-confirms-strong-potential-for-new-diamond-jewellery-category-in-China.html.

Ruby necklace tops Christie's first China auction (2013) Jewellery News Asia, Sept. 27, http://www.jewellerynewsasia.com/ en/search/search_result/8873/Ruby-necklace-tops-Christie-sfirst-China-auction.html.

Schuster K. (2012) The world's largest jewelry retailer. Rapaport Magazine, http://www.diamonds.net/Magazine/Article.aspx? ArticleID $=39994 \&$ RDRIssueID $=90$.

Shanghai Gold Exchange (2011) China gold report 2011. http://www.sge.sh/publish/sgeen/docs/20121129150156292870.pdf.

_ (n.d.) SCE overview. http://www.sge.sh/publish/sgeen/ sge_brief/sge_overview/7216.htm.

Shenzhen steps up role in jewellery manufacturing (2012) Jewellery News Asia, http://www.jewellerynewsasia.com/en/News/ 6000/Shenzhen-steps-up-role-in-jewellery-manufacturing.html.

Silver Institute (2012) The Chinese Silver Market. London: Thomson Reuters. http://www.uschina.org/sites/default/files/Chinese SilverMarket2012.pdf.

Sina Corporation (2013) The past ten years of the Chinese gold market, http://finance.sina.com.cn/focus/pdhisn.

Sims D. (2013) China widens lead as world's largest manufacturer. Industry Market Trends, March 14, http://news.thomasnet.com/ IMT/2013/03/14/china-widens-lead-as-worlds-largestmanufacturer.

Skoyles J. (2013a) How China is taking over the world, one gold bar at a time. The Real Asset Co., Sept. 30, http://therealasset.co.uk/ china-gold-bar-takeover/.

(2013b) Uncovering China's rush for gold. The Real Asset Co., Oct. 3, http://therealasset.co.uk/china-rush-gold/October 3.

Skuse A. (2014) WeChat: The Chinese chat app stealing Weibo's thunder. CNN, Feb. 27, http://edition.cnn.com/2014/02/27/ business/tencent-wechat-unseats-sina-weibo/.
Song L. (2009) Guidance, tasks and focus on strengthening the reform of China's tax system. Review of Economic Research, No. 26, Nov. 10, http://d.wanfangdata.com.cn/periodical_jiyjck 200926001.aspx [in Chinese].

Sun M, Nie N. (2008) The industry association of the nine famous "Yinlou" in Shanghai. Vision, Vol. 55, http://www.ciicvision.com/contents/855/1524.html [in Chinese].

Survey finds China manufacturing hits 2-year high (2013) Yahoo! News, Jan. 24, http://news.yahoo.com/survey-finds-china-manufacturing-hits-035747538.html.

Tian Y.P., Fan P.J. (2012) The current situation of China's human resource development. China Internet Information Center, Dec. 24, http://guoqing.china.com.cn/2012-12/24/content 27495444.htm [in Chinese].

Tourmaline grips Chinese collectors (2013) Jewellery News Asia, Sept. 24, http://www.jewellerynewsasia.com/en/search/search_ result/8813/Tourmaline-grips-Chinese-collectors.html.

United Nations Statistics Division (2013) Commodity trade statistics database, http://data.un.org/Data.aspx?q=China++Pearls\& $\mathrm{d}=$ ComTrade $\& \mathrm{f}=\_11$ Code $\% 3 \mathrm{a} 72 \% 3$ brtCode $\% 3 \mathrm{a} 156$.

Wang S., Pfanner E. (2013) China's one-day shopping spree sets record in online sales. New York Times, Nov. 11, http://www.nytimes.com/2013/11/12/business/international/onlineshopping-marathon-zooms-off-the-blocks-in-china.html?_r=0.

Wen W.Y. (2012) Future of platinum and platinum jewelry market in China. Gems \& Jewelry Trade Association of China Annual Meeting Report, http://biz.ifeng.com/zhubaowang/zhubaohangye/tebiezhuanti/2012baoxienianhui/hangyejigoufayan/ detail_2012_12/16/484028_0.shtml [in Chinese].

Woetzel J., Li X.L., Cheng W. (2012) What's next for China? McKinsey Insights China, http://www.mckinsey.com/insights/ asia-pacific/whats_next_for_china.

World Bank (2013) Gross domestic product 2012. Dec. 17, 2012, http://databank.worldbank.org/data/download/GDP.pdf.

World Gold Council (2013) China. http://www.gold.org/jewellery/ markets/china/.

Xiong M.L. (2013) Jadeite market-ups and downs, CCTV video, from "Economy 30 minutes," posted Oct. 3, http://tv.cntv.cn/ video/C10329/50d62f5c7b384a9d8cf6f2843a2cf406 [in Chinese].

Yang M.X. (2013) Gemology higher-education and general education: Current situation and the future. Presented at the International Colored Gemstone Association Congress, Changsha, China, http://www.gemstone.org/images/files/congress2013/ speaker/03Congress2013_Yang\%20Mingxing.pdf [in Chinese].

Zhang B.L. (2006) Systematic Gemmology. Beijing: Geological Publishing House.

Zhang D. (2008) Reflection: The past 30 years of the Chinese jewelry industry. Globrand, Dec. 21, http://www.globrand.com/2008/ 96789.shtml [in Chinese].

Zheng J. (2013) Friendly competition. Rapaport Magazine, http://www.diamonds.net/Magazine/Article.aspx?ArticleID=44 070\&RDRIssueID $=113 \&$ ArticleTitle=China . 